\title{
In Vivo knockdown of Basal Forebrain p75 Neurotrophin Receptor Stimulates Choline Acetyltransferase Activity in the Mature Hippocampus
}

Authors: Graham L Barrett*, Timur Naim, Jennifer Trieu and Mengjie Huang

Department of Physiology

University of Melbourne (

Victoria 3010

Australia

Corresponding author: grahamlb@unimelb.edu.au Tel: 61-3-8344 5869

Running Title: p75 $^{\mathrm{NTR}}$ Regulates Hippocampal ChAT Activity

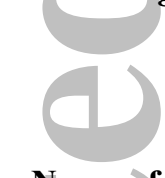

Name of Associate Editor for Submission: Dr. Jean de Vellis or Dr. Rahmi Bansal

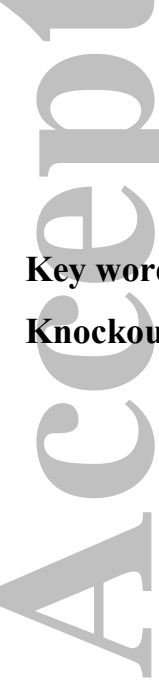

This work was supported by the National Health and Medical Research Council of Australia (Project grant no. 628491) and by Circadian Ltd.

This is the author manuscript accepted for publication and has undergone full peer review but has not been through the copyediting, typesetting, pagination and proofreading process, which may lead to differences between this version and the Version record. Please cite this article as doi:10.1002/jnr.23717. 


\section{ABSTRACT}

We sought to determine whether knockdown of basal forebrain p75 Neurotrophin Receptor $\left(\mathrm{p} 75^{\mathrm{NTR}}\right.$ ) expression would elicit increased hippocampal choline acetyltransferase (ChAT) activity in mature animals. Antisense oligonucleotides (oligos) targeting p $75^{\mathrm{NTR}}$ were infused into the medial septal area of mature rats continuously for 4 weeks. In all rats, the cannula outlet was placed equidistant between the left and right sides of the Vertical Diagonal Band of Broca (VDB). We tested phosphorothioate (PS), morpholino (Mo) and gapmer (mixed PS/RNA) oligos. Gapmer antisense infusions of $7.5 \mu \mathrm{g} /$ day and $22 \mu \mathrm{g} /$ day decreased septal p $75^{\mathrm{NTR}}$ mRNA by $34 \%$ and $48 \%$, respectively. The same infusions increased hippocampal ChAT activity by $41 \%$ and $55 \%$. Increased hippocampal ChAT activity correlated strongly with septal $\mathrm{p} 75^{\mathrm{NTR}}$ downregulation in individual rats. Infusions of PS and Mo antisense oligos did not downregulate $\mathrm{p} 75^{\mathrm{NTR}}$ mRNA or stimulate ChAT activity. These results demonstrate that $\mathrm{p} 75^{\mathrm{NTR}}$ can dynamically regulate hippocampal ChAT activity in the mature central nervous system. They also reveal the different efficacies of three diverse antisense oligo chemistries, when infused intra-cerebrally. Of the three types, gapmer oligos worked best. (

\section{SIGNIFICANCE}

A feature of Alzheimer's disease and normal ageing is declining function of the cholinergic cells that modulate the function of hippocampal neurons. This decline contributes to the memory impairment seen in both conditions. Much of our current AD medication is aimed at inhibiting acetylcholine breakdown, but there is considerable interest in developing new therapies to stimulate the cholinergic cells themselves, to maintain hippocampal function. We show that by targeting $\mathrm{p} 75^{\mathrm{NTR}}$, we can increase cholinergic activity in the hippocampus. This is likely to stimulate hippocampal function and thereby improve memory, and may become an exciting new area of drug development 


\section{INTRODUCTION}

Studies of $\mathrm{p} 75^{\mathrm{NTR}}$ knockout models have revealed increased numbers of cholinergic neurons in the basal forebrain (Barrett et al., 2010; Greferath et al., 2000; Naumann et al., 2002; Yeo et al., 1997), and hypertrophy of cholinergic forebrain neurons (Greferath et al., 2012; Yeo et al., 1997). Similar findings were reported in both of the $\mathrm{p} 75^{\mathrm{NTR}}$ knockout models that have been described extensively in the literature: One model has a truncating insertion in the $3^{\text {rd }}$ exon (Lee et al., 1992), while the other has a truncation in the $4^{\text {th }}$ exon (von Schack et al., 2001). Further studies on the $3^{\text {rd }}$ exon model have revealed increased choline acetyltransferase (ChAT) activity in the hippocampus and neocortex (Greferath et al., 2012;

Yeo et al., 1997) and an increase in the number of acetylcholinesterase - positive fibres in the hippocampus (Greferath et al., 2000; Yeo et al., 1997). Greater dendritic complexity and dendritic spine density in hippocampal neurons was found in both knockout models (Zagrebelsky et al., 2005). These findings led us to propose that $\mathrm{p} 75^{\mathrm{NTR}}$ is a negative regulator of the trophic state of the cholinergic basal forebrain system (Greferath et al., 2012). It remains possible, however, that the cholinergic enhancement of the knock-out is a purely developmental phenomenon, not indicative of $\mathrm{p} 75^{\mathrm{NTR}}$ function in the mature nervous system. We sought to determine whether $\mathrm{p} 75^{\mathrm{NTR}}$ exerts negative regulation on the cholinergic system in normal mature animals. To test this, we needed to "knock down" $p 75^{\mathrm{NTR}}$ in mature animals that had developed in the presence of normal levels of $\mathrm{p} 75^{\mathrm{NTR}}$. We decided to use antisense oligonucleotides directed against $\mathrm{p} 75^{\mathrm{NTR}} \mathrm{mRNA}$, and to infuse them directly into the medial septal region in normal mature rats For in vitro downregulation, the antisense approach has largely been superseded by RNA interference (RNAi) techniques. RNAi has also been successfully applied to in vivo work, but achieving robust results requires certain properties of the target cells and tissue. The cholinergic basal forebrain is a particularly unfavourable target tissue (see Discussion). There are numerous reports of the successful application of $\mathrm{p} 75^{\mathrm{NTR}}$ antisense DNA oligos in whole animal in vivo experiments (Cheema et al., 1996; Epa et al., 2000; Lowry et al., 2001). For the present study, performed in living mature rats, we therefore chose to use antisense oligonucleotides to downregulate $\mathrm{p} 75^{\mathrm{NTR}}$ gene expression in the basal forebrain.

We anticipated that sustained downregulation of $\mathrm{p} 75^{\mathrm{NTR}}$ would be required to produce a measurable phenotypic change. To assess the effect of antisense treatment, we measured ChAT activity in the target field of septal neurons, i.e. hippocampus. ChAT activity has proven over decades of cholinergic research to be a reliable assay of cholinergic function (Contestabile et al., 2008; Wu and Hersh, 1994). In previous work on p $75^{\mathrm{NTR}}$ knockout mice, 
hippocampal ChAT activity was found to be upregulated by $77 \%$ in homozygous knockouts (no functional $\mathrm{p} 75^{\mathrm{NTR}}$ allele), and by $38 \%$ in heterozygous mice (one functional allele)

(Barrett et al., 2010).

The increase in ChAT activity in heterozygotes is noteworthy, in that antisense oligos can downregulate their target proteins by $40 \%$ to $75 \%$ (Epa et al., 2001), comparable to the amount by which $\mathrm{p} 75^{\mathrm{NTR}}$ is reduced in the heterozygote brain, compared to the wild-type (Murphy et al., 2015).

We elected to use three different types of antisense oligo, all with the same antisense sequence. In addition to conventional phosphorothioate (PS) oligos, we used a hybrid RNA/DNA oligonucleotide known as a gapmer. The more sophisticated design of the gapmer allows the advantages of different oligo technologies to be incorporated into a single oligo. We also included a morpholino (Mo) antisense oligo. Mo oligos are highly resistant to nucleases, but are not substrates for RNAse H. Their antisense efficacy relies upon translational steric hindrance.

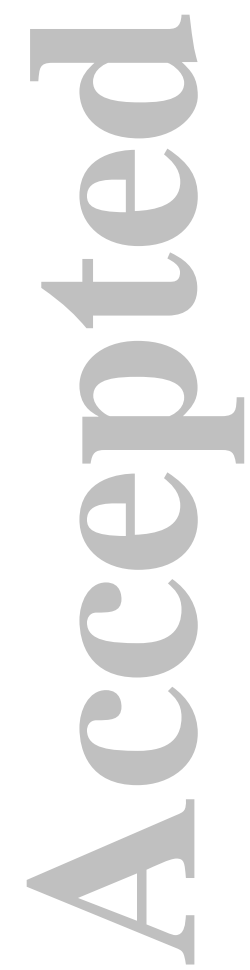




\section{METHODS}

Mature female rats were divided into treatment groups, as summarized in table 1 . The rats were aged between 6 and 12 weeks old at the start of the experiment. Oligonucleotides at the appropriate concentration were dissolved in phosphate buffered saline (PBS) and loaded into Alzet 2004 minipumps (Alzet, Cupertino, CA) by fine needle injection. Three concentrations of gapmer oligos, spanning one log scale and corresponding to injection rates of $22 \mu \mathrm{g} /$ day, $7.5 \mu \mathrm{g} /$ day and $2.5 \mu \mathrm{g} / \mathrm{day}$, were used. The wide dosage range reflects the paucity of literature information about direct CNS infusion of gapmer antisense oligos, and thus of the optimal doses with regard to toxicity and efficacy. The same concentrations were used for PS oligos, with the omission of the highest dosage ( $22 \mu \mathrm{g}$ /day) group due to toxicity concerns (see Discussion). The third type of antisense oligo used in this study, the Mo oligo, was infused at the medium level only, i.e., $7.5 \mu \mathrm{g} /$ day.

There were two control groups for the experimental (antisense) compounds: one was the vehicle (PBS) infusion; the other was the non-sense, or scrambled sequence, oligonucleotide.

This oligo contained the same nucleotides as the antisense oligo, but in scrambled order. Separate PS and gapmer non-sense oligos were made. The importance of using non-sense oligos with the same chemistry as the antisense oligos was to aid in distinguishing antisense effects from non-specific oligonucleotide effects. Due to the large number of experimental groups, complexity of the surgery, and technical difficulty of achieving uninterrupted 4-week CNS infusions, we did not use a Mo non-sense oligo, and infused the Mo antisense at only one dosage level.

\section{Details of Antisense Oligonucleotides}

The antisense sequence used in all experiments was the 19mer:

ACCTGCCCTCCTCATTGCA, directed against a segment of the rat $\mathrm{p} 75^{\mathrm{NTR}}$ mRNA that spans the start codon. The scrambled, or non-sense oligonucleotide sequence, was also a 19mer, with the same base constituents as the antisense oligo, but arranged in a scrambled order : CTCCCACTCGTCATTCGAC. The gapmer, PS and Mo antisense oligos all used the antisense sequence given above; the gapmer and PS non-sense oligos both used the non-sense sequence indicated above. The gapmer structure consisted of short segments of PS DNA at the 5'and 3' ends, surrounding an inner core, or gap, of modified RNA residues. The gapmer oligos, were made to order by Sigma-Genosys (USA), and supplied in HPLC-purified form. The PS oligos were synthesized in our own laboratory, on an ABI 392 DNA synthesizer 
using standard phosphoramidite reagents (ABI, USA), and the sulfurizing reagent TETD (ABI, USA). Trityl and protecting groups were removed at the end of the synthesis procedures, and the PS oligos were purified by reverse-phase HPLC using an acetonitrile gradient in water, with $1 \%$ triethylammonium. The Mo antisense oligo was purchased in HPLC-purified form from Gene Tools (Philomath, OR, USA). As mentioned, we did not include a Mo non-sense oligo.

Oligos were supplied or prepared in lyophilized form. All oligos were initially reconstituted in TE to a concentration of $0.75 \mathrm{mM}$, based on the mass of lyophilized oligo and their respective molecular weights (5948 daltons for the PS antisense oligo, 6061 for the gapmer and 6306 for the morpholino). Dissolution of the oligos was carried out for several hours with shaking at room temperature, then allowed to continue overnight at 4 degrees Celsius, to ensure completion of the dissolving process. Actual oligo concentrations were assessed by OD260 readings (OD254 for the Mo oligo), and oligos were further diluted in PBS to the concentrations required for the 3 chosen dosage levels. Accordingly the Alzet model 2004 minipumps, which deliver 6.0 microlitres per day for at least 28 days, were filled with oligo solutions of $0.6 \mathrm{mM}, 205 \mu \mathrm{M}$ and $68 \mu \mathrm{M}$. The highest concentration corresponds to a dosage of 3.6 nanomoles/day ( $22 \mu \mathrm{g} / \mathrm{day})$. The next concentration corresponds to 1.23 nanomoles/day, or $7.5 \mu \mathrm{g} /$ day. The lowest concentration yields a daily dose of 0.41 nanomoles/day, equal to $2.5 \mu \mathrm{g} / \mathrm{day}$.

\section{Gapmer Design}

The 19 bases of the antisense (and nonsense) sequence are linked by 18 nucleotide linkages. The bases themselves are unmodified; the intricacies of chemical modifications of the gapmer occur solely within the sugar component of the central segment and the inter-nucleotide linkagès of the two wing segments (figure 1). The 5' and 3' wings each consist of 5 DNA nucleosides interconnected by 4 PS linkages. The 9 linkages forming the central part are normal phosphodiesters, but the associated sugar group is modified ribose, rather than 2'deoxy ribose. The central part thus consists of RNA, with a methyl substitution at the 2' hydroxyl group. The resultant nucleosides are commonly known as 2'- methoxy RNA residues.

PS nucleotides have the advantage of relative resistance to 5'and 3'exonucleases, with retention of RNAse H substrate activity. The minimum length of DNA segment to support RNAse H activity has been reported to be 4-5 residues (Crooke et al., 1995; Juliano et al., 
2005; Lima and Crooke, 1997), with some variability according to the position of the DNA segment within the oligo (Crooke et al., 1995). Binding of PS DNA to the target results in a DNA:RNA duplex in which the RNA strand become a substrate for RNAse H. The endonuclease action of RNAse $\mathrm{H}$ divides the mRNA component of the duplex, and this leads to exonuclease attack on the exposed ends of the fragmented mRNA, resulting in rapid degradation. This is believed to be the major mechanism by which antisense DNA oligonucleotides downregulate their targets. The major disadvantage of PS oligos is that nonspecific binding to proteins is much greater than with PO oligonucleotides, with unpredictable consequences which may (and very often do) mask or overwhelm the antisense effect. A further disadvantage of PS oligos is relatively weak duplex formation with the target RNA sequence.

2'-modified RNA oligonucleotides, used in the centre of the gapmer, have several attractive

properties (Cummins et al., 1995; Inoue et al., 1987; Lesnik and Freier, 1998; Monia et al., 1993). The 2'- methoxy substitution produces oligos with very strong annealing characteristics. The 2'modifications also give rise to a significant degree of protection against nucleases, so that they are much more stable in plasma and extracellular fluid, than RNA itself.

\section{Animal Surgery and Intracerebral Infusions of Oligonucleotides}

Female Sprague-Dawley Rats (RRID: RGD_737903), weighing between 275 and $330 \mathrm{~g}$ at the commencement of surgery, were used. Anaesthetized rats were placed into a stereotaxic frame. The top of the head was shaved in the area around the lambda and bregma sutures. Our objective was to place the cannula tip precisely in the midline, in the MS/VDB region (figure 2). We wanted the cannula tip to be close to the MS and VDB, since both contribute to hippocampal innervation; for practical reasons it was located in the VDB, but in close proximity to the MS. A vertical midline approach to cannula insertion could not be used, due to the presence of longitudinal midline blood vessels beneath the skull. The burr hole in the skull was made at an offset of $0.7 \mathrm{~cm}$ lateral to the midline, $0.8 \mathrm{~mm}$ rostral to bregma. The cannula apparatus was inserted at a precise angle and distance to achieve the desired midline VDB placement of the cannula tip. The cannula length inside the skull was $7.3 \mathrm{~mm}$, and was set at an angle of 19 degrees from vertical. The cannula manifold was attached to the skull with cyanoacrylate glue. An Alzet osmotic minipump (model 2004) was implanted between the scapulae, and joined to the cannula via $1 \mathrm{~mm}$ diameter polyethylene tubing. Correct placement of the cannula outlet was verified by performing a series of cannulations in which 
Trypan Blue was infused (supplementary information fig S1). Post mortem analysis confirmed correct and consistent placement of the point of infusion, in the midline of the VDB. All procedures were approved by the animal ethics committees of The University of Melbourne. Rats were kept on a 12h light: $12 \mathrm{~h}$ dark cycle schedule and housed in groups of one to three per cage. The rats were given food and water ad libitum during housing and treated humanely throughout.

\section{Dissection of Septum}

The septum was dissected whole from each rat, without separation of the right from left, since it was impossible to do so accurately. The MS/VDB is a midline structure in which cholinergic neurons of the right side may be only several microns from their counterparts of the left. Even the most careful dissection with minimal scalpel force causes sufficient tissue deformation to make accurate separation of right and left impossible. Removal of the whole septum, encompassing the lateral septum, medial septum and VDB, was straightforward, since it separates along natural tissue planes from the corpus callosum dorsally, the lateral ventricles dorso-laterally, and the striatum laterally. To achieve consistency in the rostral and caudal extents of the septal slice, the brain was cut by coronal slice $2 \mathrm{~mm}$ rostral to the cannula entry site; a caudal coronal slice was made at the site of confluence of the anterior commissures, equivalent to the mid-point of the optic chiasm at bregma $-0.2 \mathrm{~mm}$. The resultant $3 \mathrm{~mm}$ thick middle slice was removed, and the septum teased away from the neighboring structures described above. In this way we were confident of consistently capturing the full extent of the MS/VDB, and a consistent amount of non-cholinergic lateral septum in each case. Consistency of dissection was necessary for the validity of the PCR controls - housekeeping genes which are expressed in all neurons, whether cholinergic or not, and glia.

\section{Measurement of $\mathrm{p}^{\mathrm{NTR}} \mathrm{mRNA}$}

We used quantitative PCR to measure mRNA in homogenates of bilateral septa, since it was not possible to accurately and consistently separate left from right halves of septa. Our method of quantification was based on the comparative Ct method (Bustin, 2002; Livak and Schmittgen, 2001; Pfaffl, 2001), with extra modifications of our own. RNA was extracted from each septum, and treated with DNAse (Promega, Madison, Wisconsin, USA) for 20 minutes in the presence of RNAsin ribonuclease inhibitor (Promega). Reverse transcription was performed on $1 \mu \mathrm{g}$ of undegraded RNA per $20 \mu \mathrm{l}$ reaction, at 42 degrees Celsius for 30 
minutes. The reaction mixture contained Superscript III reverse transcriptase (Invitrogen, www.thermofisher.com), $2.5 \mathrm{mM}$ of each dNTP, $100 \mu \mathrm{M}$ random hexamers, $25 \mathrm{mM}$ dithiothreitol and 2 units of RNAsin ribonuclease inhibitor. The reaction was terminated by heat denaturation (75 degrees, 5 minutes). One microlitre of cDNA was added to a microcentrifuge tube containing Applied Biosystems SYBR-green premix

(www.thermofisher.com) and amplified by real-time quantitative PCR (qPCR). qPCR was performed in a Corbett Rotor Gene 2000 (Corbett Research, St Neots, UK), using 40 cycles of 94 degrees for 20 seconds, 60 degrees for 5 seconds and 68 degrees for 10 seconds. A two minute denaturation step was performed at the beginning of the first cycle, and a cooling step after the $40^{\text {th }}$ cycle. Basic analysis of PCR results was carried out using the software package supplied with the machine. The conventional approach to comparative $\mathrm{Ct}$ is to choose a "housekeeping gene" and use its mRNA level as a normalization factor. The assumption is that expression of the housekeeping gene is constant. However, studies have shown this assumption to be invalid for many of the housekeeping genes that have been used (Schmittgen and Zakrajsek, 2000; Tricarico et al., 2002). We used two approaches to minimize artefacts arising from imperfect controls. First, and most importantly, the same RNA concentration was used in every reverse transcription reaction, across the whole study. This measure is only useful if the RNA is of a uniformly high quality throughout. This necessitates adherence to a policy of strict quality control. All RNAs were tested by agarose gel electrophoresis, stained by ethidium bromide, and assessed by the intactness and lack of smearing of the $18 \mathrm{~S}$ and $28 \mathrm{~S}$ ribosomal RNA bands. Samples which showed unequivocal evidence of degradation were discarded. In samples with distinct and strong $28 \mathrm{~S}$ and $18 \mathrm{~S}$ bands but a minor or borderline degree of smearing, we deemed them acceptable if the 28S:18S intensity ratio $>1.4$. A degree of RNA degradation can be tolerated if amplicon size is kept small (generally agreed to mean less or equal to $100 \mathrm{bp}$ ) (Bustin, 2002). Secondly, it is necessary to control for failures of reverse transcription or variations between quality of PCR mixes (including variations in Taq Polymerase activity). This is usually done by measuring a single housekeeping gene in parallel with the gene of interest. As discussed above, this can lead to misleading results. We therefore monitored both a housekeeping gene, and 18S RNA. We chose Glycerol-3-phosphate dehydrogenase (GAPDH) as the housekeeping gene. The expression level of each RNA, (p75 ${ }^{\mathrm{NTR}}$ mRNA, GAPDH mRNA and 18S RNA) was based on the conventional method of taking the $\mathrm{Ct}$ point in each real time run. The $\mathrm{Ct}$ values for GAPDH and 18S RNA were converted to their antilog values, then normalized (to avoid 
unequal weighting caused by the high level of $18 \mathrm{~S}$ RNA) and averaged, and this number was converted to its $\log$ equivalent to obtain a "reference $\mathrm{Ct}$ ". This value was derived for each RNA sample, and used as the control for the $\mathrm{Ct}$ of the target gene $\left(\mathrm{p} 75^{\mathrm{NTR}}\right)$. The mean value of $\mathrm{p} 75^{\mathrm{NTR}}$ mRNA in the group treated with gapmer nonsense $7.5 \mu \mathrm{g} / \mathrm{day}$, with each value adjusted according to its own reference $\mathrm{Ct}$, was arbitrarily set to unity. The mean $\mathrm{p} 75^{\mathrm{NTR}}$ mRNA value for all other groups was then expressed relative to the gapmer nonsense group. The primer pairs and amplicon sizes were as follows: $\mathrm{p} 75^{\mathrm{NTR}}$ (5'-CAGACCCATACGCAGACT-3', 5'-ACCTCCTCACGCTTGGT-3', amplicon size 89 bp); GAPDH (GTGAAGGTCGGTGTGAA, CGTTGATGGCAACAATGT, amplicon 95 bp); 18S RNA (GTAACCCGTTGAACCCCATT, CCATCCAATCGGTAGTAGCG, amplicon 121 BP)

\section{Measurement of Choline Acetyltransferase Activity}

ChAT assays were performed as previously described (Greferath et al., 2012). Briefly, dissection of left and right whole hippocampi was carried out. The hippocampi were placed on ice, and divided into 5 equidistant segments by making 4 scalpel cuts normal to the long axis. The first (most dorsal), $3^{\text {rd }}$ (middle) and $5^{\text {th }}$ (most ventral) segments were pooled and snap frozen, using liquid nitrogen immersion, and transferred to a -84 degrees Celsius freezer for subsequent ChAT assay. The second and forth segments were placed in formalin fixative, to allow the possibility of subsequent histochemistry (not performed). ChAT assays were performed within a week of freezing. The left and right hippocampi of each rat were measured separately, and their ChAT activities were regarded as independent items of data. Thus the group of 7 rats that were treated with $7.5 \mu \mathrm{g} /$ day of gapmer antisense oligos yielded 14 data points $(n=14)$ for hippocampal ChAT activity. We felt this was justified by the results of the PBS control group, and the nonsense oligo-treated groups, in which the degree of correlation between ChAT activities of left and right hippocampi was statistically insignificant.

\section{Statistics}

The effects of the various treatment regimes on ChAT activity were analysed by one-way ANOVA using Minitab (State College, PA, USA) version 16. Pairwise comparisons were then done by Tukey's post-hoc method, again using Minitab software. Correlations between datasets (e.g., between ChAT activities of the right and left hippocampi in control animals) were assessed by regression analysis with ANOVA, using Minitab version 16. 


\section{RESULTS}

\section{Downregulation of $\mathrm{p}^{\mathrm{NTR}} \mathrm{mRNA}$ in rats treated with gapmer antisense (AS) oligos.}

Real time PCR was used to measure $\mathrm{p} 75^{\mathrm{NTR}}$ mRNA levels in the dissected whole septum of treated rats at the end of the 4 week infusion period. Rats were treated with continuous 4week infusions of PBS or gapmer oligos at one of three dose levels (figure 3A). The tip of the delivery cannula was positioned in the midline of the VDB, close to the junction of the MS, to enable bilateral downregulation of $\mathrm{p} 75^{\mathrm{NTR}}$ in cholinergic MS and VDB neurons. The slice of septum was taken from the confluence of the anterior commissures to a point $3 \mathrm{~mm}$ rostral to this, and contained the entire bilateral MS/VDB region. The amount of noncholinergic lateral septal tissue in this slice was considerable, but was consistent from animal to animal. Whilst it was easy to separate the septum from surrounding structures, it was in practice impossible to accurately separate the left from right components. We therefore report mRNA levels that reflect the aggregate of both sides, rather than separate measurements of right and left. The level of $\mathrm{p} 75^{\mathrm{NTR}}$ mRNA relative to housekeeping gene RNA was measured using the delta-delta $\mathrm{Ct}$ method for quantification. Two housekeeping RNAs (18S RNA and GAPDH mRNA) were measured in each septum, and their combined values were converted to a reference $\mathrm{Ct}$, as described in Methods. The mean value of the $\mathrm{p} 75$ :housekeeping quotient for the group that received gapmer nonsense (NS) oligos at $7.5 \mu \mathrm{g}$ /day was arbitrarily set to unity, and the values for all other groups are relative to this group. Analysis by one-way ANOVA showed a significant main effect of gapmer oligo treatment on $\mathrm{p} 75^{\mathrm{NTR}}$ mRNA. (N (total number of rats) $=43, \mathrm{~F}_{6,36}=4.22, \mathrm{p}<0.005$ ). Using Tukey's post-hoc comparisons, we found that $\mathrm{p} 75^{\mathrm{NTR}}$ mRNA was significantly lower in the $7.5 \mu \mathrm{g}$ /day gapmer antisense group: $0.66 \pm 0.12$ versus $1.0 \pm 0.11$ in the equivalent nonsense group $(\mathrm{N}=6$ (NS) \& 7 (AS), $\mathrm{p}$ $<0.01$ ). In other words, $\mathrm{p} 75^{\mathrm{NTR}}$ mRNA was downregulated by $34 \%$. In the group that received gapmer antisense at $22 \mu \mathrm{g} / \mathrm{day}, \mathrm{p} 75^{\mathrm{NTR}}$ mRNA was downregulated by $48 \%$, relative to the gapmer nonsense $22 \mu \mathrm{g}$ /day group $(\mathrm{N}=4$ per group, $\mathrm{p}<0.01)$. The $\mathrm{p} 75$ mRNA levels of the $7.5 \mu \mathrm{g} /$ day and $22 \mu \mathrm{g} /$ day gapmer antisense groups were also significantly reduced with respect to the PBS group.

\section{Effect of 3 oligo chemistries on p $^{\mathrm{NTR}}$ mRNA levels}

Neither the PS or Mo antisense oligos decreased $\mathrm{p} 75^{\mathrm{NTR}}$ mRNA compared to the PS nonsense or the PBS groups (figure 3B). In the case of the Mo oligo, this was to be expected, since Mo oligos do not activate the RNAse $\mathrm{H}$ mechanism, but work via steric hindrance of 
translation. Unlike the other two oligo types, Mo oligos can downregulate the target protein without concomitant mRNA downregulation

\section{Hippocampal ChAT Activity. 1. Control Rats; Lack of correlation between left and} right hippocampi. We aimed to deliver antisense reagents precisely to the midline of the anterior part of the basal forebrain, in the region that contains the cholinergic neurons that project via the fornix to the hippocampus. Any inaccuracy in placement could bias the antisense perfusion to one side, leading to asymmetrical $\mathrm{p} 75^{\mathrm{NTR}}$ downregulation in the left and right $\mathrm{MS} / \mathrm{VDB}$. According to our working hypothesis, that $\mathrm{p} 75^{\mathrm{NTR}}$ downregulation stimulates ChAT synthesis, asymmetric perfusion would be reflected in asymmetrical effects on ChAT activity in the left and right hippocampi. If it could be assumed that, for a given animal, the initial ChAT activities of the left and right hippocampi were equal, then disparities between left and right hippocampal ChAT activities at the end of the treatment period could be used to assess deviations from equality of antisense dosing between the two sides of the basal forebrain. It was therefore important to ask whether left and right hippocampal ChAT activities were highly correlated in individual control animals. In the PBS control group, the infusion of $6 \mu$ of buffered saline per day is not likely to have any impact on ChAT expression, regardless of possible deviations from perfectly symmetrical infusion of the two sides of the basal forebrain. There was no correlation between left and right hippocampal ChAT activities in individual rats, however, as shown by the scatter plot (figure 4A). The Pearson correlation coefficient (r) was just 0.23 and statistically insignificant $(p=0.6$, ANOVA). The regression equation was ChAT (Right) $=141+0.135 \times$ ChAT (Left) but the value of R-squared, the regression coefficient of determination, was small and statistically insignificant $\left(\mathrm{R}^{2}=0.051, \mathrm{n}=8, \mathrm{~F}_{1,6}=0.32, \mathrm{p}=0.59\right.$. It is evident that the ChAT activities of left and right hippocampi in control rats were essentially independent of each other. This perhaps surprising result means that the variation of hippocampal ChAT activity between rats was no greater than the variation between right and left within rats. The sample size of PBS rats was rather small, however. As we shall discuss below, the hippocampal ChAT activity of rats that were treated with gapmer control (nonsense) oligos at $2.5 \mu \mathrm{g} / \mathrm{day}$ and at $7.5 \mu \mathrm{g} / \mathrm{day}$ did not differ significantly from the PBS group, nor from each other. This enabled us to pool these 3 groups (i.e., PBS, gapmer nonsense $2.5 \mu \mathrm{g} /$ day and gapmer nonsense $7.5 \mu \mathrm{g} / \mathrm{day}$ ), to increase the sample size for comparison of right versus left CHAT activity within individual rats. The resulting scatter plot, obtained from the pooling of these 3 groups, again revealed a 
lack of correlation between left and right hippocampal ChAT activities (figure 4B). The value of the correlation coefficient $r$ was 0.28 and statistically insignificant $(p=0.18$, ANOVA). The regression equation was ChAT (Right) $=115+0.265 \times$ ChAT (Left) but the coefficient of determination, $R$-squared, was small and statistically insignificant $\left(\mathrm{R}^{2}=0.08\right.$, $\mathrm{n}=21, \mathrm{~F}_{1,19}=1.94, \mathrm{p}=0.18$ ). This lack of correlation between ChAT activities of hippocampi in individual rats meant that we could not use post-infusion differences to gauge the extent of asymmetrical dosing of left and right in single animals. In another respect, the lack of correspondence was an advantage: it meant that each hippocampus could be considered as an individual entity for statistical purposes. This had the effect of doubling the sample size $\mathrm{N}$ in each treatment group.

\section{Gapmer $75^{\mathrm{NTR}}$ antisense oligos stimulate hippocampal ChAT activity relative to nonsense and PBS-treated controls}

In these analyses, we did not combine right and left hippocampal ChAT values to obtain an aggregate value for each rat. Each hippocampus was considered an independent unit, since there was no significant correlation between right and left hippocampi in untreated (control) rats, as described in the preceding section. There was a significant main effect of gapmer oligo treatment on hippocampal ChAT activity, as revealed by one-way ANOVA analysis $(\mathrm{N}$ $=86$, treatment effect $\left.\mathrm{F}_{6,79}=11.13, \mathrm{p}<0.0001\right)$. Further analysis by Tukey's post-hoc tests revealed that gapmer antisense at $7.5 \mu \mathrm{g} /$ day and at $22 \mu \mathrm{g} /$ day stimulated hippocampal ChAT activity, relative to PBS and to nonsense treated groups (figure 5A). At $7.5 \mu \mathrm{g} / \mathrm{day}, \mathrm{p} 75^{\mathrm{NTR}}$ antisense caused a $41 \%$ increase in hippocampal ChAT activity relative to the cognate nonsense group ( $\mathrm{N}=12(\mathrm{NS}) \& 14(\mathrm{AS}), \mathrm{p}<0.01)$. At $22 \mu \mathrm{g} /$ day, $\mathrm{p} 75^{\mathrm{NTR}}$ antisense elicited a $55 \%$ increase in ChAT activity, relative to the same dose of nonsense gapmer oligo $(\mathrm{N}=8$ per group, $\mathrm{p}<0.05)$. At $2.5 \mu \mathrm{g} /$ day, however, $\mathrm{p} 75^{\mathrm{NTR}}$ antisense infusion had no observed effect on hippocampal ChAT, relative to nonsense treatment or PBS treatment.

\section{PS oligos suppress ChAT activity, but this effect is non-sequence-specific.}

PS oligos were infused at $2.5 \mu \mathrm{g} /$ day and $7.5 \mu \mathrm{g}$ /day (figure 5B). Dosages greater than 7.5 $\mu \mathrm{g} /$ day were not used in the present study, due to concerns about toxicity (see Discussion). Infusion of PS oligos clearly had an effect on hippocampal ChAT activity, relative to PBS, as shown by the highly significant main treatment effect $\left(\mathrm{N}=54\right.$, treatment effect $\mathrm{F}_{4,49}=20.12$, $\mathrm{p}<0.0001$ ). Post-hoc comparisons by Tukey's method revealed no differences between any 
of the 4 PS oligo-treated groups. All 4 PS oligo groups, however, had significantly lower ChAT activity than the PBS control group ( $\mathrm{p}<0.05$ for each of the 4 comparisons). Thus the suppression of ChAT activity by PS oligos was not sequence specific, and clearly not an antisense effect.

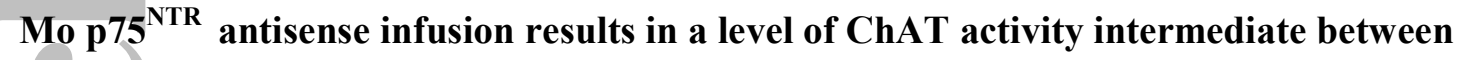 PS and gapmer antisense oligos.}

Inclusion of the Mo antisense group allowed us to compare the effects obtained by 3 different antisense chemistries (figure 5C). The Mo p $75^{\mathrm{NTR}}$ antisense oligo was infused at $7.5 \mu \mathrm{g} / \mathrm{day}$, since experience with other oligos suggested this dose to be the best compromise between maximizing antisense efficacy and minimizing toxic effects (i.e., non-sequence-specific suppression of ChAT activity). It is clear, however, that Mo antisense treatment did not stimulate hippocampal ChAT activity compared to the PBS or gapmer nonsense groups. The omission of a Mo nonsense group was therefore of no practical consequence. In the 5 group comparison of figure $4 \mathrm{C}$, ANOVA revealed a strong main effect of treatment $\left(\mathrm{N}=74, \mathrm{~F}_{4,69}=\right.$

$36.6, \mathrm{p}<0.0001$ ), but only the gapmer antisense oligo increased hippocampal ChAT relative to the PBS and gapmer nonsense groups $(\mathrm{p}<0.05)$. In view of the ANOVA's strong treatment effect, the failure of Mo oligo treatment to produce any effect on ChAT level suggests that these oligos did not significantly change the level of $\mathrm{p} 75^{\mathrm{NTR}}$ protein.

\section{Level of p75NTR Expression is Inversely Correlated to Hippocampal ChAT Activity} There was a significant inverse correlation between septal $\mathrm{p} 75^{\mathrm{NTR}}$ mRNA expression and bilateral ChAT activity in rats treated with gapmer $\mathrm{p} 75^{\mathrm{NTR}}$ antisense oligos (figure 6). The R-squared value ( $36.8 \%$ ) suggests that at least $37 \%$ of the difference in ChAT activities could be attributed to the antisense-mediated downregulation of $\mathrm{p} 75^{\mathrm{NTR}}$ mRNA. Not surprisingly, there was no evidence of correlation between $\mathrm{p} 75^{\mathrm{NTR}}$ mRNA downregulation and ChAT activity in rats treated with PS or Mo antisense oligos.

\section{DISCUSSION}

We used gapmer antisense oligos to downregulate $\mathrm{p} 75^{\mathrm{NTR}}$ mRNA in the septum of mature rats, and showed that this caused a significant increase in hippocampal ChAT activity. Moreover, there was a correlation between the degree of $\mathrm{p} 75^{\mathrm{NTR}}$ mRNA downregulation, and the magnitude of the increase in ChAT activity. This is consistent with the increased ChAT 
activity (and cholinergic hypertrophy) found in $\mathrm{p} 75^{\mathrm{NTR}}$ knockout animals, but extends the knockout findings by showing that the inverse relationship between p75NTR expression and ChAT activity is not solely a developmental phenomenon. The functionality of the cholinergic system that innervates the hippocampus of normal, mature animals is also subject to negative regulation by $\mathrm{p} 75^{\mathrm{NTR}}$ expression.

The two hippocampi of each rat were treated as separate and independent entities for statistical purposes, since their ChAT activities showed no correlation to each other. This may be a novel finding; it does not seem to have been noted in any previous rat studies. It may also be an artefact of the left-sided cannulation, although this is unlikely since the cannula did not make contact with either the fimbrio-fornix or hippocampus.

\section{Role of $\mathrm{p}^{\mathrm{NTR}}$}

The concept that cholinergic basal forebrain $\mathrm{p} 75^{\mathrm{NTR}}$ promotes effects opposite to those usually attributed to neurotrophins, has emerged from studies of the Exon III and Exon IV p $75^{\text {NTR }}$ knockout mice. Knockout studies are limited in what they can tell us about function of a gene product in the mature organism. To determine unequivocally the postdevelopmental role of $\mathrm{p} 75^{\mathrm{NTR}}$, it is necessary to modulate its expression in a mature animal that has developed with a normal spatio-temporal pattern of $\mathrm{p} 75^{\mathrm{NTR}}$ expression. In the present study we investigated the effect of knocking down $\mathrm{p} 75^{\mathrm{NTR}}$ expression in normal adult rats, by measuring hippocampal ChAT activity.

The gapmer data was clear-cut. We observed $\mathrm{p} 75^{\mathrm{NTR}}$ mRNA downregulation with the gapmer oligo, at doses of $7.5 \mu \mathrm{g} /$ day and $22 \mu \mathrm{g} /$ day. Reducing gene expression of $\mathrm{p} 75^{\mathrm{NTR}}$ in the septal VDB region of the basal forebrain caused enhancement of cholinergic activity in the hippocampus. We infer from this that $\mathrm{p} 75^{\mathrm{NTR}}$ acts as a brake or suppressor on the level of cholinergic activity in the mature brain.

Recently, Coulson and coworkers used the cre-lox system to investigate the effects of reducing or ablating $\mathrm{p} 75^{\mathrm{NTR}}$ expression in postnatal animals, isolated from the developmental sequelae of conventional p75 ${ }^{\mathrm{NTR}}$ knockouts (Boskovic et al., 2014). Their findings supported the consensus view that $\mathrm{p} 75^{\mathrm{NTR}}$ has a negative role in the basal forebrain, in agreement with studies of knockout animals (Barrett, 2000; Greferath et al., 2000; Naumann et al., 2002; Walsh et al., 1999; Yeo et al., 1997). An interesting point of difference was the absence, in the cre-lox study, of any clear effect of $\mathrm{p} 75^{\mathrm{NTR}}$ on hippocampal function. A number of groups have shown major effects of $\mathrm{p} 75^{\mathrm{NTR}}$ on the hippocampus (Krol et al., 2000; Salama- 
Cohen et al., 2005; Woo et al., 2005; Zagrebelsky et al., 2005). It may be argued in some cases that these were primarily developmental effects of $\mathrm{p} 75^{\mathrm{NTR}}$. An alternative explanation for the discrepancy is that the lack of hippocampal phenotype was due to incomplete cre-loxdriven inactivation of $\mathrm{p} 75^{\mathrm{NTR}}$ in VDB cholinergic neurons: Cre recombination in cholinergic neurons apparently varied between $60 \%$ and $90 \%$ in individual animals (Rossi et al., 2011),

but Coulson and co-workers point out that they used animals only from strains with the higher recombination frequencies. There was no information on spatial variation in recombination efficiency between the different parts of the cholinergic basal forebrain. Another possible cause for the discrepancy in results is that the Morris water maze is a less sensitive cognitive test than the Barnes maze, due to greater inputs from confounding physical fitness and stress variables. Based on the history of investigations on the original p $75^{\mathrm{NTR}}$ knockout, it is likely to require further work to unlock the secrets of the new cre-lox animal developed by Coulson and co-workers. One clear finding from the cre-lox model of Coulson's group is that neocortical ChAT levels are dependent upon p $75^{\mathrm{NTR}}$, such that reduction or ablation of $\mathrm{p} 75 \mathrm{NTR}$ expression leads to elevated ChAT activity. This is consistent with findings by Longo's group some years ago (Yeo et al., 1997).

\section{Secondary Study: Comparison of intra-cerebral efficacy of 3 antisense chemistries}

To improve our chances of successfully targeting $\mathrm{p} 75^{\mathrm{NTR}}$ by intra-cerebral infusion, we used three different antisense chemistries. The extra work involved in performing the same basic experiment in triplicate, with three types of antisense oligo, enabled us to compare the efficacy of these oligos for direct intra-cerebral delivery.

We chose to use an oligonucleotide sequence directed against the 5'region of the coding sequence of the mRNA, including the initiation codon, because this antisense oligonucleotide has consistently produced downregulation of $\mathrm{p} 75^{\mathrm{NTR}} \mathrm{mRNA}$ and protein in a variety of celltypes and tissues, both in vitro and in vivo.(Barrett and Bartlett, 1994; Barrett and Georgiou, 1996; Cheema et al., 1996; Epa et al., 2000; Epa et al., 2004; Lowry et al., 2001; Soilu-

Hanninen et al., 2000). The same sequence was used in each of the 3 antisense chemistries.

\section{Choice of Types of Antisense Oligos}

The majority of published antisense experiments have used DNA oligos with an all-PS backbone. The PS modification confers nuclease resistance whilst retaining RNAse $\mathrm{H}$ compatibility, potentially causing scission of the target mRNA. The chief disadvantage of PS oligos has proven to be a high degree of "stickiness" to proteins, leading to unpredictable 
oligo-protein interactions. The proclivity of PS oligos to produce phenotypical effects as a result of oligo-protein interactions led to a negative perception of antisense as an experimental tool. Initially hailed as magic bullets, antisense experiments came to be viewed by many as inherently unreliable and often misleading. Intensive developmental efforts have since led to improved antisense technologies with reduced non-specificity and greater antisense efficacy. Two of the most popular of the new generation (often called third generation) antisense technologies are gapmer oligos and morpholino (Mo) oligos. We restricted the present study to just three antisense chemistries: We used PS oligos, despite their shortcomings, because they have been successful in delineating $\mathrm{p} 75^{\mathrm{NTR}}$ function in neurons of the peripheral nervous system, both in vivo and in vitro (Barrett and Bartlett, 1994; Barrett and Georgiou, 1996; Barrett et al., 1998; Cheema et al., 1996). Additionally, we used gapmers and Mo oligos. All oligos were administered by continuous intra-cerebral infusion for 4 weeks.

\section{Oligo efficacy}

Only the gapmer produced reliable $\mathrm{p} 75^{\mathrm{NTR}}$ mRNA downregulation, and the modest degree of downregulation that was achieved required surprisingly high doses. PS oligos, on the other hand, were not effective. We avoided very high doses of PS oligos, in view of reports that they have toxic effects on brain tissue (Le Corre et al., 1997; Peng Ho et al., 1998). In the present study, even at the low-to-medium dose ranges of 2.5 and $7.5 \mu \mathrm{g} / \mathrm{day}$, PS oligos had non-sequence-specific effects that lowered ChAT production and failed to downregulate p $75^{\text {NTR }}$ mRNA.

As would be expected, morpholino oligos, which work only by translational hindrance, and do not activate RNAse H-mediated mRNA lysis, did not show any effects on $\mathrm{p} 75^{\mathrm{NTR}}$ mRNA levels. More importantly, they did not produce an elevation in ChAT levels.

\section{Why not RNAi?: Rationale for Use of Antisense Oligos}

It has been well documented that there are many problems and pitfalls associated with the use of antisense oligonucleotides to reduce gene expression (Agrawal, 1999; Agrawal and Iyer, 1997; Benimetskaya et al., 1995; Henry et al., 1999; Juliano et al., 2005). RNA interference (RNAi) has become the preferred means of reducing gene expression, particularly in vitro. The successful deployment of RNAi usually involves virus-mediated introduction of vectors into cells, where they express antisense RNA strands that hybridize with the mRNA target. 
Unfortunately the virus approach is not well suited to the cholinergic basal forebrain system. The cholinergic neurons are not an anatomically compact group; they are widely dispersed and are intermingled with many other neurons, including GABAergic and glutamatergic neurons. The widely disseminated, sparse localization of cholinergic neurons presents a major impediment to the use of viral RNAi: It is essentially impossible to target more than a small portion of basal forebrain cholinergic neurons with a virus introduced from a point source; the vastly higher molecular weight of an adenovirus, for example (approx. 150,000 kilodaltons) relative to an oligo (6 kilodaltons) - a mass ratio of 25,000 to one means that its diffusibility will be much lower. Several point sources would be required to comprehensively target the MS and VDB neurons that project to the hippocampus. This would entail several cannulation sites, adding greatly to the experimental difficulty, variability and scope for error. In our view, this makes the viral RNAi approach unfeasible. Another well-known RNAi technique employs double stranded RNA oligonucleotides, sometimes in conjunction with lipofection to assist uptake. This approach has not been successful in vivo, since RNA oligos are rapidly degraded by extracellular and intracellular nucleases. Moreover, the modifications that are used to make oligos nuclease-resistant, such as the PS backbone, are often incompatible with RNAi mechanisms (Juliano et al., 2005; Kanasty et al., 2013). It was therefore not feasible to undertake this in vivo study with RNAi.

\section{Significance}

The finding that targeting $\mathrm{p} 75^{\mathrm{NTR}}$ in the MS/VDB of mature animals stimulates ChAT activity in the hippocampus is important, because pathology of the septo-hippocampal system, and of closely related medial temporal structures, is intimately connected to the pathogenesis of AD. Moreover, the septo - hippocampal system is of fundamental importance in memory function. NGF has long been seen as a candidate therapeutic agent in senile dementia, but has proven problematic in many ways. There is ongoing interest in neurotrophin mimetics as putative therapeutics, but successful drugs have yet to emerge. The present report strongly endorses

the case for $\mathrm{p} 75^{\mathrm{NTR}}$ as an alternative therapeutic target by which to stimulate cholinergic activity and thereby achieve positive cognitive outcomes in AD. 


\section{Figure Legends}

1. Chemical structure of "inverted gapmer" oligonucleotides. A. The central core segment is composed of modified RNA residues. These residues differ from normal RNA residues only in that the 2' hydroxyl group is replaced by a methoxy group. B. The antisense and nonsense control versions consisted of short "wings" of PS DNA surrounding the 9 residue 2'

methoxy RNA central segment. There are 5 DNA residues at the 5' end and 5 DNA residues at the 3' end. C. Sequence and linkage summary of the antisense and nonsense inverted gapmers. The presence of DNA segments means that the mRNA:oligo duplex formed with the target $\mathrm{p} 75^{\mathrm{NTR}}$ message will be a substrate for the enzyme RNAse H. The PS linkages confer resistance to exonucleases. The 2' methoxy RNA segment confers high annealing affinity and also adds endonuclease-resistance. Each oligo contains just 8 sulfur atoms, reducing the extent of non-specific protein interactions compared to a 19-mer PS oligo, which contains 18 sulfurs. S indicates the sulfur of a PS linkage, and O indicates a phosphodiester linkage.

2. Placement of minipump and cannula. Stereotaxic positioning was employed to position the outlet of the cannula in the midline of the VDB, with the aim of achieving equal diffusion to cholinergic projection neurons on the left and right sides. The cannula manifold was cemented in the skull $0.7 \mathrm{~cm}$ lateral to the midline, to avoid major blood vessels. The cannula (inside-skull length $7.3 \mathrm{~mm}$ ) was fixed at an angle of 19 degrees from vertical to achieve the desired outlet positioning. Inset (upper): Thin $(1 \mathrm{~mm})$ tubing was routed subcutaneously from the Alzet 2004 minipump, located in subcutaneous tissue between the scapulae and adjacent to the spine, and joined to the proximal end of the cannula. Inset (lower): an expanded view of the cannula outlet in the VDB. According to our working hypothesis, bilateral downregulation of $\mathrm{p} 75^{\mathrm{NTR}}$ mRNA in the VDB would cause bilateral increases in hippocampal ChAT activity. Cross-sectional diagram of rat brain adapted from The Rat Brain in Stereological Coordinates (Paxinos and Watson, 2005).

3. Downregulation of $\mathrm{p} 75^{\mathrm{NTR}}$ mRNA in the septum of rats treated with gapmer oligo infusions. The ddCt method was used to quantify and compare levels of septal $\mathrm{p} 75^{\mathrm{NTR}}$ mRNA under various treatments. The mean value of $\mathrm{p} 75^{\mathrm{NTR}}$ mRNA in the group treated with gapmer nonsense $7.5 \mu \mathrm{g}$ /day was arbitrarily set to unity, so all other values are relative to this. Means \pm s.e.m. are displayed. A. Gapmer oligos. One-way ANOVA showed a 
significant main effect of treatment on $\mathrm{p}^{\mathrm{NTR}}$ mRNA $\left(\mathrm{F}_{6,36}=4.22, \mathrm{p}<0.005\right)$. From left to right, the $\mathrm{N}$ value for each group is $8,7,7,6,7,4$ and $4 . \quad \mathrm{p} 75^{\mathrm{NTR}}$ mRNA was reduced by $34 \%$ in rats treated with $7.5 \mathrm{mg} /$ day antisense, and by $48 \%$ in rats treated with $22 \mathrm{mg} /$ day antisense (relative to commensurate nonsense-treated groups). * Asterisks indicate significant decreases in the number of $\mathrm{p} 75^{\mathrm{NTR}}$ mRNA molecules in antisense- relative to non-sensetreated animals, ( $p<0.05$, ANOVA with Tukey's post-hoc comparisons). B. The effect of three antisense chemistries - PS, gapmer and Morpholino (Mo) - on p75 ${ }^{\mathrm{NTR}}$ mRNA levels. One-way ANOVA indicated the presence of a main effect of treatment $\left(\mathrm{F}_{4,32}=3.17, \mathrm{p}<\right.$ $0.05)$. From left to right, $\mathrm{N}=8,6,8,7$ and 8 for the respective treatment groups. After infusion at $7.5 \mathrm{mg} /$ day for 4 weeks, only the gapmer antisense oligo reduced $\mathrm{p} 75^{\mathrm{NTR}}$ mRNA significantly, compared to PBS controls ( $\mathrm{p}<0.05$, Tukey's post-hoc test) and to gapmer nonsense controls (also infused at $7.5 \mathrm{mg} /$ day).

4. Hippocampal ChAT activity in controls, left versus right. The scatter plot compares left and right hippocampi of individual rats. Each point gives the ChAT activity (in units of pmol $\mathrm{ACh} / \mathrm{min} / \mathrm{mg}$ tissue) of the left hippocampus on the horizontal axis, and that of the corresponding right hippocampus on the vertical axis. A. Only PBS-treated rats are shown. The regression equation is ChAT (Right) $=141+0.135 \times$ ChAT (Left) $p=0.59 . \mathrm{R}^{2}$ (the regression co-efficient of determination) $=0.051 . \mathrm{N}=8, \mathrm{~F}_{1,6}=0.32, \mathrm{p}=0.59$. There is essentially no correlation between the two hippocampal ChAT activities in individual control animals (correlation coefficient $=0.23, \mathrm{p}=0.6$, ANOVA).), but the sample size is small. $\mathbf{B}$. To allow a larger survey, rats treated with gapmer nonsense oligos at 2.5 and $7.5 \mu \mathrm{g} /$ day were pooled with PBS controls, since there were no differences in hippocampal ChAT activity between any of these 3 groups. Again, there was no statistically significant correlation between left and right hippocampal ChAT activities (correlation coefficient = $0.28, \mathrm{p}=0.18$, ANOVA). The regression equation is ChAT (Right) $=115+0.265 \mathrm{x}$ ChAT (Left). $\mathrm{N}=21, \mathrm{~F}_{1,19}=1.94, \mathrm{p}=0.18$. The regression co-efficient $\mathrm{R}^{2}=0.08$.

5. Effect on hippocampal ChAT activity of gapmer, PS and Morpholino $\mathrm{p} 75^{\mathrm{NTR}}$ antisense oligos, delivered by continuous infusion into the basal forebrain for 4 weeks. The oligos were delivered to the midline of the basal forebrain, between the right and left VDB, as shown in figure 2. The two hippocampi of each animal were not combined, but treated as individual units. Means \pm s.e.m. are displayed. A. Gapmer $p 75^{\mathrm{NTR}}$ antisense oligos were 
infused at three different dosage levels. One-way ANOVA revealed a strong main effect of treatment on ChAT activity $\left(\mathrm{F}_{6,79}=11.13, \mathrm{p}<0.001\right) . \mathrm{N}=16,14,14,12,14,8$ and 8 , respectively, for the 7 groups from left (PBS) to right (AS $22 \mu \mathrm{g} /$ day). Double asterisks indicate that hippocampal ChAT activity increased significantly in the gapmer antisense 7.5 $\mu \mathrm{g} /$ day and $22 \mu \mathrm{g} /$ day groups, compared to the respective non-sense-treated groups $(\mathrm{p}<0.01$, One-way ANOVA with Tukey's post-hoc comparisons). B. Effect of 4-week infusion of PS antisense oligos at two different dosage levels. Dosing higher than $7.5 \mu \mathrm{g}$ per day was not undertaken, due to toxicity concerns. One-way ANOVA revealed a significant main effect of treatment on ChAT activity $\left(\mathrm{F}_{4,49}=20.12, \mathrm{p}<0.001\right) . \mathrm{N}=16,6,6,10$ and 16 , respectively, for the 5 groups from left (PBS) to right (AS $7.5 \mu \mathrm{g} /$ day). Post-hoc analysis by Tukey's method revealed, however, that the only significant difference was between the control PBS group and the four PS oligo - treated groups. There were no pairwise differences between any of the four PS oligo - treated groups. No stimulatory effects of antisense oligos on ChAT activity were observed. ChAT activity was suppressed, relative to PBS controls, in all groups treated with PS oligos, regardless of whether antisense or random (nonsense) sequence oligos were used. Asterisks indicate that ChAT activity decreased significantly, compared to the PBS group ( $\mathrm{p}<0.05$, One-way ANOVA with Tukey's post-hoc comparisons).

C. Comparison of three antisense oligos - PS, gapmer and Morpholino (Mo) - infused at 7.5 $\mu \mathrm{g} /$ day for 4 weeks. For comparison, two control groups are shown; i.e., PBS and gapmer nonsense $(7.5 \mu \mathrm{g} /$ day). There was no morpholino nonsense group. One-way ANOVA revealed a strong main effect of treatment on ChAT activity $\left(\mathrm{F}_{4,69}=36.6, \mathrm{p}<0.001\right) . \mathrm{N}=16$, $12,16,14$ and 16, for the groups from left to right. Single asterisk * indicates that PS antisense treatment reduced ChAT activity significantly, compared to the PBS and gapmer nonsense groups $(\mathrm{p}<0.05$, Tukey's post-hoc test)). Double asterisks $* *$ indicates that gapmer antisense increased hippocampal ChAT relative to the PBS and gapmer nonsense groups $(\mathrm{p}<$ 0.01 , Tukey's post-hoc test). Morpholino antisense oligos did not cause any significant difference in ChAT activity, relative to either of the two control groups (Tukey's post-hoc test)

6. Scatter plots of bilateral hippocampal ChAT activity (obtained from the average of left and right hippocampi in each rat) and septal $\mathrm{p} 75^{\mathrm{NTR}}$ mRNA in the same rat, in antisense-treated animals. Data was taken from rats treated with $7.5 \mu \mathrm{g} /$ day and (for gapmer) $22 \mu \mathrm{g} /$ day. A. There was a significant correlation in rats treated with gapmer antisense. The regression 
equation was $\mathrm{ChAT}=290-105 \times \mathrm{p} 75^{\mathrm{NTR}}$ mRNA level. Further regression analysis by analysis of variance in MATLAB revealed that the co-efficient R-squared of the regression line was $36.8 \%$, and this was statistically significant $\left(n=11, \mathrm{~F}_{1,9}=5.24, \mathrm{p}<.05\right)$. This means that at least $37 \%$ of the difference in ChAT activities can be attributed to the antisensemediated downregulation of $\mathrm{p} 75^{\mathrm{NTR}}$ mRNA. B. No correlation between ChAT and $\mathrm{p} 75^{\mathrm{NTR}}$ mRNA was evident in PS antisense-treated animals. The regression equation was ChAT $=$ $101-10.7 \times \mathrm{p} 75^{\mathrm{NTR}}$ mRNA level. The value of R-squared was $3.5 \%$ and not statistically significant $\left(n=8, F_{1,6}=0.22, p=0.66\right)$. C. No correlation was evident in morpholino antisense-treated animals. The regression equation was ChAT $=120+15.8 \times \mathrm{p} 75^{\mathrm{NTR}} \mathrm{mRNA}$ level, and R-squared $=2.0 \%(\mathrm{n}=8, \mathrm{~F}=0.12, \mathrm{p}=0.74)$.

\section{Conflict of interest statement}

The authors have no actual or potential conflicts of interest

\section{Role of authors.}

"All authors had full access to all the data in the study and take responsibility for the integrity of the data and the accuracy of the data analysis.

Study concept and design: GB, JT, TN

Acquisition of data: TM, JT, GB, MH

Analysis and interpretation of data: GB, TN, JT, MH

Drafting of the manuscript: GB

Critical revision of the manuscript for important intellectual content: GB

Statistical analysis: GB, MH

Obtained funding: GB 


\section{SUPPLEMENTARY INFORMATION. Caption for Figure S1}

Fig S1. Correct placement of the cannula outlet was verified by performing a series of cannulations in which Trypan Blue was infused via osmotic minipumps. The surgical procedure was exactly the same as that used for oligos. Trypan blue is likely to have a higher diffusibility in tissue than the highly charged and higher MW oligonucleotides. Therefore the pictures may not portray the actual displacement of infused antisense oligos. They are intended to provide qualitative evidence of bilateral penetration of the basal forebrain region from a single infusion point. A. Inferior view of the intact brain, showing bilateral distribution of trypan blue in the basal forebrain, beneath the optic chiasm. The venous system is filled with trypan blue, reflecting lymphatic drainage and capillary uptake of interstitial trypan blue. B. Magnified view of the inset of figure (A) showing evenly matched penetration of both sides of the basal forebrain. C. Another inferior view of the brain in (A), showing deep penetration bilaterally. D. Coronal view at the level of the joining of the anterior commissures, which was taken of the caudal-most point of the MS/VDB region. The inset shows that the extent of indicator penetration is consistent bilaterally. E. The basal forebrain has been dissected and the right and left sides separated to show the penetration into tissue of the indicator dye. F. Another example, similar to E.

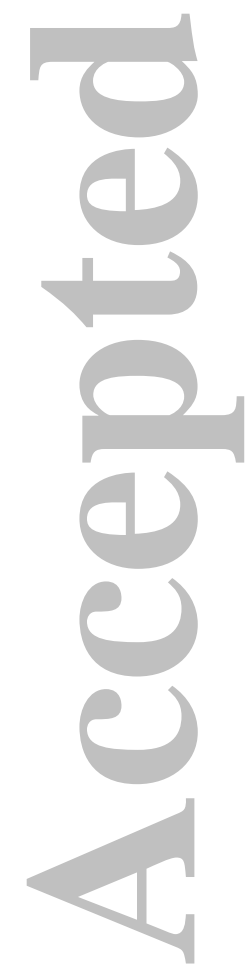




\section{REFERENCES}

Agrawal, S. (1999). Importance of nucleotide sequence and chemical modifications of antisense oligonucleotides. Biochim Biophys Acta 1489, 53-68.

Agrawal, S., and lyer, R.P. (1997). Perspectives in antisense therapeutics. Pharmacol Ther 76, 151160.

Barrett, G.L. (2000). The p75 neurotrophin receptor and neuronal apoptosis. Prog Neurobiol 61, 205229.

Barrett, G.L., and Bartlett, P.F. (1994). The p75 nerve growth factor receptor mediates survival or death depending on the stage of sensory neuron development. Proceedings of the National Academy of Sciences of the United States of America 91, 6501-6505.

Barrett, G.L., and Georgiou, A. (1996). The low-affinity nerve growth factor receptor p75(NGFR) mediates death of PC12 cells after nerve growth factor withdrawal. Journal of Neuroscience Research 45, 117-128.

Barrett, G.L., Georgiou, A., Reid, K., Bartlett, P.F., and Leung, D. (1998). Rescue of Dorsal Root Sensory Neurons By Nerve Growth Factor and Neurotrophin-3, But Not Brain-Derived Neurotrophic Factor or Neurotrophin-4, Is Dependent On the Level of the P75 Neurotrophin Receptor.

Neuroscience 85, 1321-1328.

Barrett, G.L., Reid, C.A., Tsafoulis, C., Zhu, W., Williams, D.A., Paolini, A.G., Trieu, J., and Murphy, M. (2010). Enhanced spatial memory and hippocampal long-term potentiation in p75 neurotrophin receptor knockout mice. Hippocampus 20, 145-152.

Benimetskaya, L., Tonkinson, J.L., Koziolkiewicz, M., Karwowski, B., Guga, P., Zeltser, R., Stec, W., and Stein, C.A. (1995). Binding of phosphorothioate oligodeoxynucleotides to basic fibroblast growth factor, recombinant soluble CD4, laminin and fibronectin is P-chirality independent. Nucleic Acids Res 23, 4239-4245.

Boskovic, Z., Alfonsi, F., Rumballe, B.A., Fonseka, S., Windels, F., and Coulson, E.J. (2014). The Role of p75NTR in Cholinergic Basal Forebrain Structure and Function. J Neurosci 34, 13033-13038.

Bustin, S.A. (2002). Quantification of mRNA using real-time reverse transcription PCR (RT-PCR): trends and problems. Journal of molecular endocrinology 29, 23-39.

Cheema, S.S., Barrett, G.L., and Bartlett, P.F. (1996). Reducing p75 nerve growth factor receptor levels using antisense oligonucleotides prevents the loss of axotomized sensory neurons in the dorsal root ganglia of newborn rats. Journal of Neuroscience Research 46, 239-245. 
Contestabile, A., Ciani, E., and Contestabile, A. (2008). The place of choline acetyltransferase activity measurement in the "cholinergic hypothesis" of neurodegenerative diseases. Neurochem Res 33, 318-327.

Crooke, S.T., Lemonidis, K.M., Neilson, L., Griffey, R., Lesnik, E.A., and Monia, B.P. (1995). Kinetic characteristics of Escherichia coli RNase $\mathrm{H} 1$ : cleavage of various antisense oligonucleotide-RNA duplexes. Biochem J 312 ( Pt 2), 599-608.

Cummins, L.L., Owens, S.R., Risen, L.M., Lesnik, E.A., Freier, S.M., McGee, D., Guinosso, C.J., and Cook, P.D. (1995). Characterization of fully 2'-modified oligoribonucleotide hetero- and homoduplex hybridization and nuclease sensitivity. Nucleic Acids Res 23, 2019-2024.

Epa, W.R., Barrett, G.L., and Bartlett, P.F. (2001). Oligonucleotides as inhibitors of protein synthesis. Methods in Molecular Biology 169, 223-242.

Epa, W.R., Greferath, U., Shafton, A., Rong, P., Delbridge, L.M., Bennie, A., and Barrett, G.L. (2000). Downregulation of the 75 neurotrophin receptor in tissue culture and in vivo, using betacyclodextrin-adamantane-oligonucleotide conjugates. Antisense Nucleic Acid Drug Dev 10, 469-478. Epa, W.R., Markovska, K., and Barrett, G.L. (2004). The p75 neurotrophin receptor enhances TrkA signalling by binding to Shc and augmenting its phosphorylation. J Neurochem 89, 344-353. Greferath, U., Bennie, A., Kourakis, A., Bartlett, P.F., Murphy, M., and Barrett, G.L. (2000). Enlarged Cholinergic Forebrain Neurons And Improved Spatial Learning In P75 Knockout Mice. European Journal of Neuroscience 12, 885-893.

Greferath, U., Trieu, J., and Barrett, G.L. (2012). The p75 neurotrophin receptor has nonapoptotic antineurotrophic actions in the basal forebrain. J Neurosci Res 90, 278-287.

Henry, S.P., Templin, M.V., Gillett, N., Rojko, J., and Levin, A.A. (1999). Correlation of toxicity and pharmacokinetic properties of a phosphorothioate oligonucleotide designed to inhibit ICAM-1.

Toxicol Pathol 27, 95-100.

Inoue, H., Hayase, Y., Imura, A., Iwai, S., Miura, K., and Ohtsuka, E. (1987). Synthesis and hybridization studies on two complementary nona(2'-O-methyl)ribonucleotides. Nucleic Acids Res 15, 6131-6148.

Jackson, A.L., and Linsley, P.S. (2010). Recognizing and avoiding siRNA off-target effects for target identification and therapeutic application. Nature reviews Drug discovery 9, 57-67.

Juliano, R.L., Dixit, V.R., Kang, H., Kim, T.Y., Miyamoto, Y., and Xu, D. (2005). Epigenetic manipulation of gene expression: a toolkit for cell biologists. J Cell Biol 169, 847-857.

Kanasty, R., Dorkin, J.R., Vegas, A., and Anderson, D. (2013). Delivery materials for siRNA therapeutics. Nature materials 12, 967-977. 
Krieg, A.M. (2011). Is RNAi dead? Molecular therapy : the journal of the American Society of Gene Therapy 19, 1001-1002.

Krol, K.M., Crutcher, K.A., Kalisch, B.E., Rylett, R.J., and Kawaja, M.D. (2000). Absence of p75(NTR) expression reduces nerve growth factor immunolocalization in cholinergic septal neurons. J Comp Neurol 427, 54-66.

Le Corre, S.M., Burnet, P.W., Meller, R., Sharp, T., and Harrison, P.J. (1997). Critical issues in the antisense inhibition of brain gene expression in vivo: experiences targetting the $5-\mathrm{HT} 1 \mathrm{~A}$ receptor. Neurochem Int 31, 349-362.

Lee, K.F., Li, E., Huber, L.J., Landis, S.C., Sharpe, A.H., Chao, M.V., and Jaenisch, R. (1992). Targeted mutation of the gene encoding the low affinity NGF receptor p75 leads to deficits in the peripheral sensory hervous system. Cell 69, 737-749.

Lesnik, E.A., and Freier, S.M. (1998). What affects the effect of 2'-alkoxy modifications? 1.

Stabilization effect of 2'-methoxy substitutions in uniformly modified DNA oligonucleotides.

Biochemistry 37, 6991-6997.

Lima, W.F., and Crooke, S.T. (1997). Binding affinity and specificity of Escherichia coli RNase H1:

impact on the kinetics of catalysis of antisense oligonucleotide-RNA hybrids. Biochemistry 36, 390398.

Livak, K.J., and Schmittgen, T.D. (2001). Analysis of relative gene expression data using real-time quantitative PCR and the 2(-Delta Delta C(T)) Method. Methods 25, 402-408.

Lowry, K.S., Murray, S.S., Coulson, E.J., Epa, R., Bartlett, P.F., Barrett, G., and Cheema, S.S. (2001).

Systemic administration of antisense p75(NTR) oligodeoxynucleotides rescues axotomised spinal motor neurons. J Neurosci Res 64, 11-17.

Monia, B.P., Lesnik, E.A., Gonzalez, C., Lima, W.F., McGee, D., Guinosso, C.J., Kawasaki, A.M., Cook, P.D., and Freier, S.M. (1993). Evaluation of 2'-modified oligonucleotides containing 2'-deoxy gaps as antisense inhibitors of gene expression. J Biol Chem 268, 14514-14522.

Murphy, M., Wilson, Y.M., Vargas, E., Munro, K.M., Smith, B., Huang, A., Li, Q.X., Xiao, J., Masters, C.L., Reid, C.A., et al. (2015). Reduction of p75 neurotrophin receptor ameliorates the cognitive deficits in a model of Alzheimer's disease. Neurobiol Aging 36, 740-752.

Naumann, T., Casademunt, E., Hollerbach, E., Hofmann, J., Dechant, G., Frotscher, M., and Barde, Y.A. (2002). Complete deletion of the neurotrophin receptor p75NTR leads to long-lasting increases in the number of basal forebrain cholinergic neurons. J Neurosci 22, 2409-2418.

Paxinos, G., and Watson, C. (2005). The Rat Brain in Stereotaxic Cordinates, Vol 1, 5 edn (Sydney: Academic Press). 
Peng Ho, S., Livanov, V., Zhang, W., Li, J., and Lesher, T. (1998). Modification of phosphorothioate oligonucleotides yields potent analogs with minimal toxicity for antisense experiments in the CNS. Brain Res Mol Brain Res 62, 1-11.

Pfaffl, M.W. (2001). A new mathematical model for relative quantification in real-time RT-PCR. Nucleic Acids Res 29, e45.

Rossi, J., Balthasar, N., Olson, D., Scott, M., Berglund, E., Lee, C.E., Choi, M.J., Lauzon, D., Lowell, B.B., and Elmquist, J.K. (2011). Melanocortin-4 receptors expressed by cholinergic neurons regulate energy balance and glucose homeostasis. Cell Metab 13, 195-204.

Salama-Cohen, P., Arevalo, M.A., Meier, J., Grantyn, R., and Rodriguez-Tebar, A. (2005). NGF controls dendrite development in hippocampal neurons by binding to p75NTR and modulating the cellular targets of Notch. Mol Biol Cell 16, 339-347.

Saxena, S., Jonsson, Z.O., and Dutta, A. (2003). Small RNAs with imperfect match to endogenous mRNA repress translation. Implications for off-target activity of small inhibitory RNA in mammalian cells. J Biol Chem 278, 44312-44319.

Scacheri, P.C., Rozenblatt-Rosen, O., Caplen, N.J., Wolfsberg, T.G., Umayam, L., Lee, J.C., Hughes, C.M., Shanmugam, K.S., Bhattacharjee, A., Meyerson, M., et al. (2004). Short interfering RNAs can induce unexpected and divergent changes in the levels of untargeted proteins in mammalian cells. Proc Natl Acad Sci U S A 101, 1892-1897.

Schmittgen, T.D., and Zakrajsek, B.A. (2000). Effect of experimental treatment on housekeeping gene expression: validation by real-time, quantitative RT-PCR. Journal of biochemical and biophysical methods $46,69-81$.

Soilu-Hanninen, M., Epa, R., Shipham, K., Butzkueven, H., Bucci, T., Barrett, G., Bartlett, P.F., and Kilpatrick, T.J. (2000). Treatment of experimental autoimmune encephalomyelitis with antisense oligonucleotides against the low affinity neurotrophin receptor. J Neurosci Res 59, 712-721.

Tricarico, C., Pinzani, P., Bianchi, S., Paglierani, M., Distante, V., Pazzagli, M., Bustin, S.A., and Orlando, C. (2002). Quantitative real-time reverse transcription polymerase chain reaction: normalization to rRNA or single housekeeping genes is inappropriate for human tissue biopsies. Anal Biochem 309, 293-300.

von Schack, D., Casademunt, E., Schweigreiter, R., Meyer, M., Bibel, M., and Dechant, G. (2001). Complete ablation of the neurotrophin receptor p75NTR causes defects both in the nervous and the vascular system. Nat Neurosci 4, 977-978.

Walsh, G.S., Krol, K.M., Crutcher, K.A., and Kawaja, M.D. (1999). Enhanced neurotrophin-induced axon growth in myelinated portions of the CNS in mice lacking the p75 neurotrophin receptor. Journal of Neuroscience 19, 4155-4168. 
Woo, N.H., Teng, H.K., Siao, C.J., Chiaruttini, C., Pang, P.T., Milner, T.A., Hempstead, B.L., and Lu, B. (2005). Activation of p75NTR by proBDNF facilitates hippocampal long-term depression. Nat Neurosci 8, 1069-1077.

Wu, D., and Hersh, L.B. (1994). Choline acetyltransferase: celebrating its fiftieth year. J Neurochem $62,1653-1663$.

Xiao, J., Wong, A.W., Willingham, M.M., Kaasinen, S.K., Hendry, I.A., Howitt, J., Putz, U., Barrett, G.L., Kilpatrick, T.J., and Murray, S.S. (2009). BDNF exerts contrasting effects on peripheral myelination of NGF-dependent and BDNF-dependent DRG neurons. J Neurosci 29, 4016-4022.

Yeo, T.T., Chua-Couzens, J., Butcher, L.L., Bredesen, D.E., Cooper, J.D., Valletta, J.S., Mobley, W.C., and Longo, F.M. (1997). Absence of p75NTR causes increased basal forebrain cholinergic neuron size, choline acetyltransferase activity, and target innervation. Journal of Neuroscience 17, 75947605 .

Zagrebelsky, M., Holz, A., Dechant, G., Barde, Y.A., Bonhoeffer, T., and Korte, M. (2005). The p75 neurotrophin receptor negatively modulates dendrite complexity and spine density in hippocampal neurons. J Neurosci 25, 9989-9999.

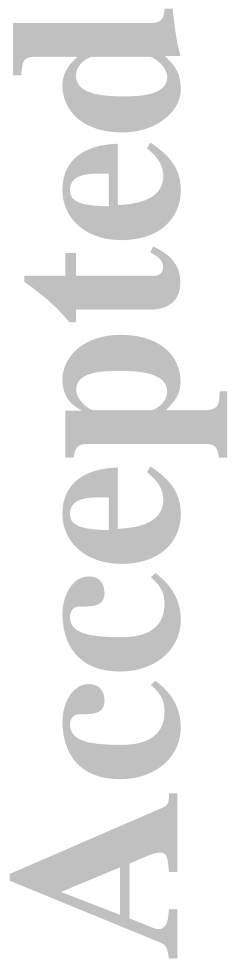


TABLE:

\section{Table I. Experimental Design}

\begin{tabular}{llllll}
\hline GROUP & Treatment & Oligo Type & Infusion Rate & N (rats) & N (hippocampi) \\
\hline $\mathbf{1}$ & PBS & ---- & $6 \mu \mathrm{L} /$ day & 8 & 16 \\
$\mathbf{2}$ & P75 antisense & Gapmer & $22 \mu \mathrm{g} /$ day & 4 & 8 \\
$\mathbf{3}$ & P75 antisense & Gapmer & $7.5 \mu \mathrm{g} / \mathrm{day}$ & 7 & 14 \\
$\mathbf{4}$ & P75 antisense & Gapmer & $2.5 \mu \mathrm{g} / \mathrm{day}$ & 7 & 14 \\
$\mathbf{5}$ & Non-sense & Gapmer & $22 \mu \mathrm{g} / \mathrm{day}$ & 4 & 8 \\
$\mathbf{6}$ & Non-sense & Gapmer & $7.5 \mu \mathrm{g} /$ day & 6 & 12 \\
$\mathbf{7}$ & Non-sense & Gapmer & $2.5 \mu \mathrm{g} /$ day & 7 & 14 \\
$\mathbf{8}$ & P75 antisense & PS & $7.5 \mu \mathrm{g} /$ day & 8 & 16 \\
$\mathbf{9}$ & P75 antisense & PS & $2.5 \mu \mathrm{g} /$ day & 3 & 6 \\
$\mathbf{1 0}$ & Non-sense & PS & $7.5 \mu \mathrm{g} /$ day & 5 & 10 \\
$\mathbf{1 1}$ & Non-sense & PS & $2.5 \mu \mathrm{g} /$ day & 3 & 6 \\
$\mathbf{1 2}$ & P75 antisense & Morpholino & $7.5 \mu \mathrm{g} /$ day & 8 & 16 \\
\hline
\end{tabular}

Rats were divided into 12 experimental groups. Three different oligo chemistries were investigated; Gapmer, phosphorothioate (PS), and morpholino (Mo). Alzet minipumps were loaded with their appropriate oligos and implanted subcutaneously. All rats, including the PBS group, received minipumps cannulated to deliver an aqueous solution to the midline of the brain between left and right VDB. All infusions were carried out for 28 days. At the completion of each infusion, the rats were killed humanely, and the septum and both hippocampi were dissected for assay procedures. 
A

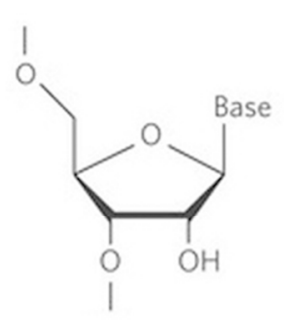

Normal RNA

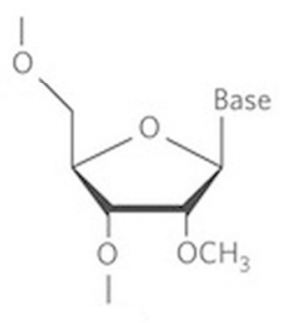

$2^{\prime}-\mathrm{OMe}$

B

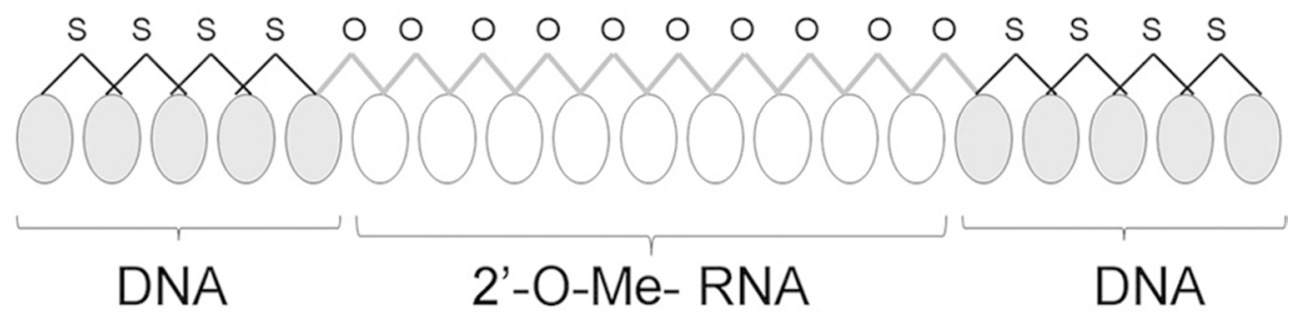

C

Oligo Sequence and Linkages

Antisense AsCsCsTsGoCoCoCoUoCoCoUnoCoAoTsTsGsCsA

Nonsense CsTsCsCsCoAoCoUn CoGoUn CoAoUoTsCsGsAsC

$83 \times 81 \mathrm{~mm}(300 \times 300 \mathrm{DPI})$

Journal of Neuroscience Research

This article is protected by copyright. All rights reserved. 
Fig 2

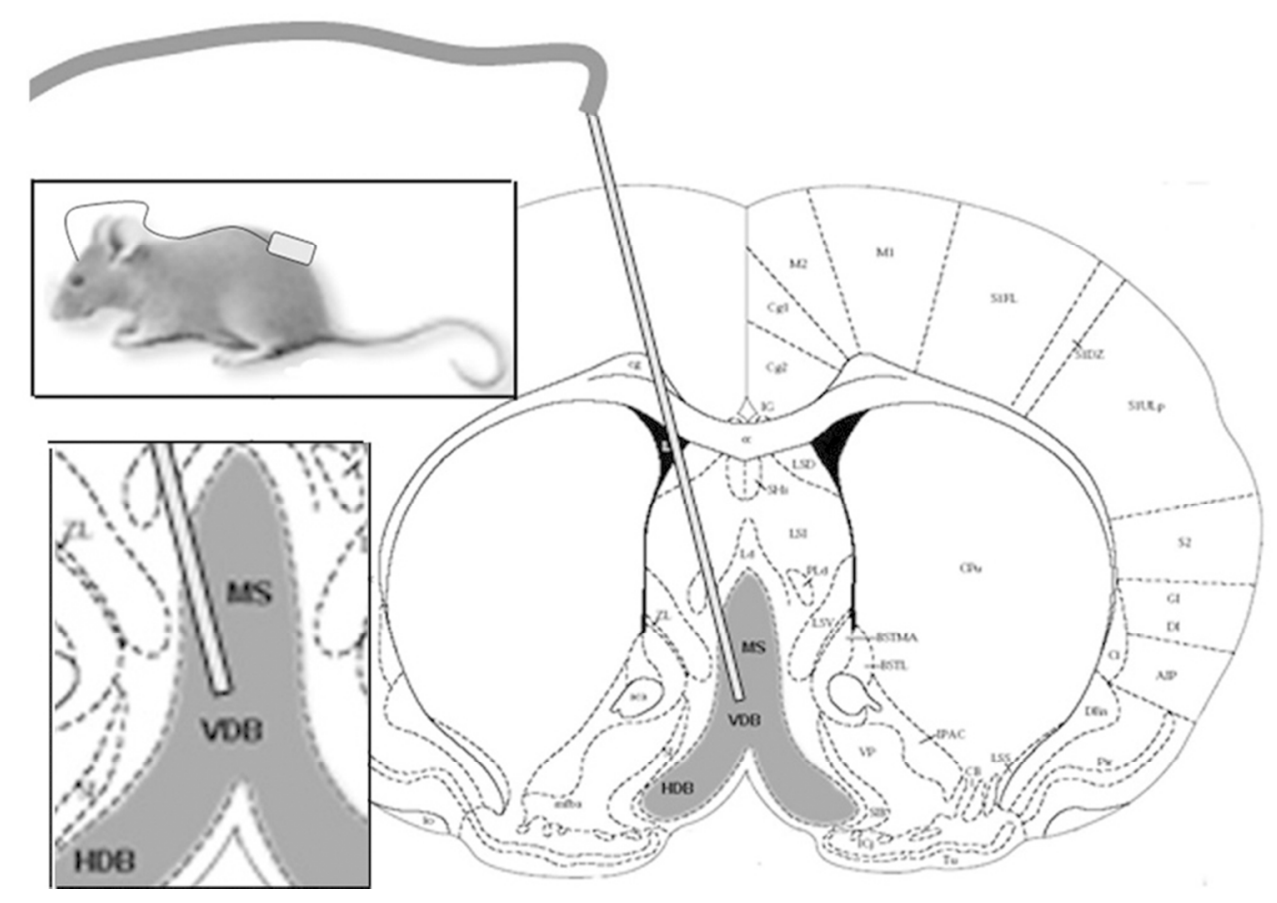

$83 \times 74 \mathrm{~mm}(300 \times 300$ DPI $)$

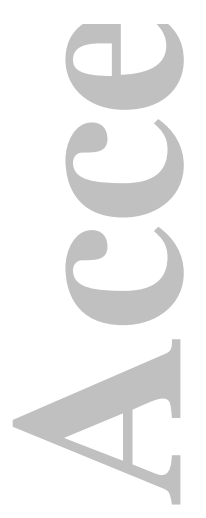

Journal of Neuroscience Research

This article is protected by copyright. All rights reserved. 
figure 3

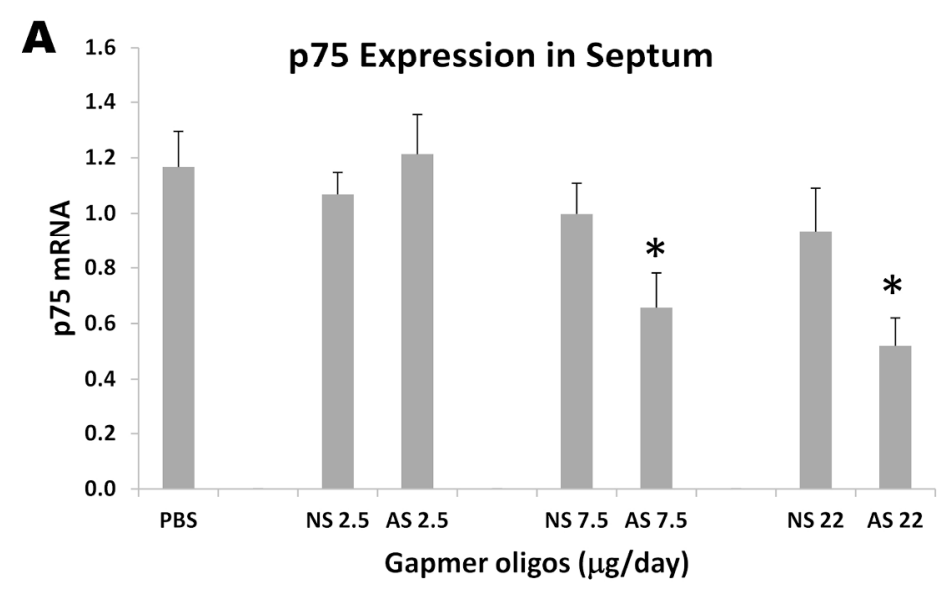

B

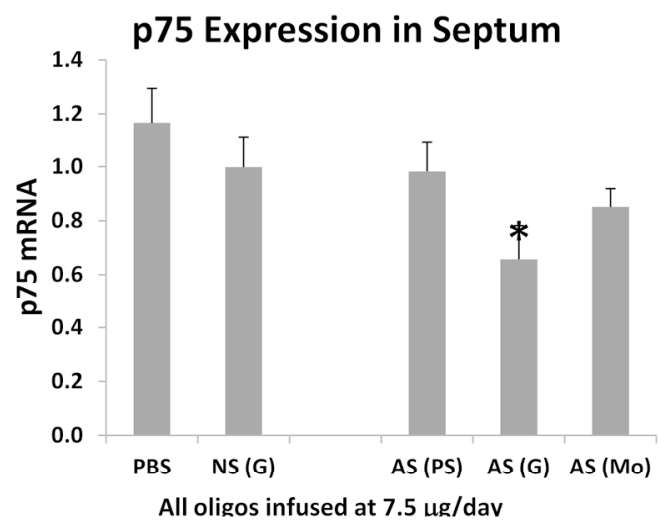

Fig 3

$170 \times 279 \mathrm{~mm}(300 \times 300 \mathrm{DPI})$

Journal of Neuroscience Research

This article is protected by copyright. All rights reserved. 
figure 4

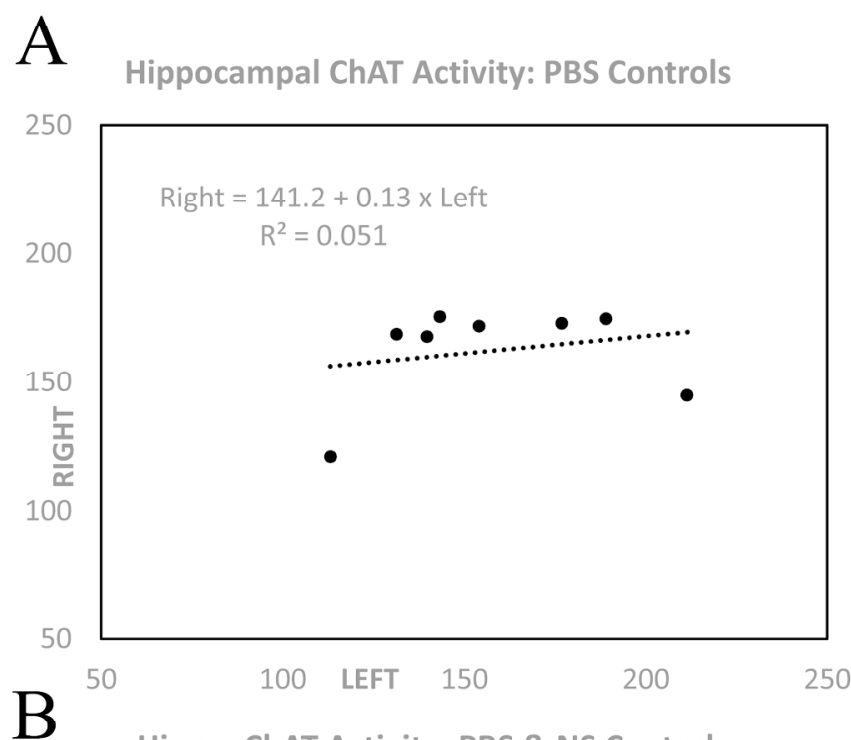

Hippo. ChAT Activity: PBS \& NS Controls

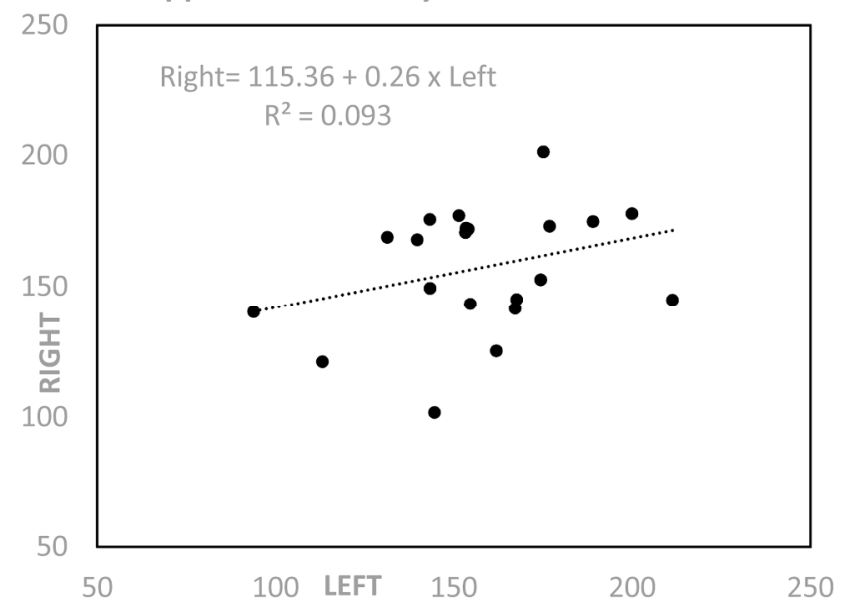

Fig 4 $166 \times 272 \mathrm{~mm}(300 \times 300$ DPI $)$

Journal of Neuroscience Research

This article is protected by copyright. All rights reserved. 

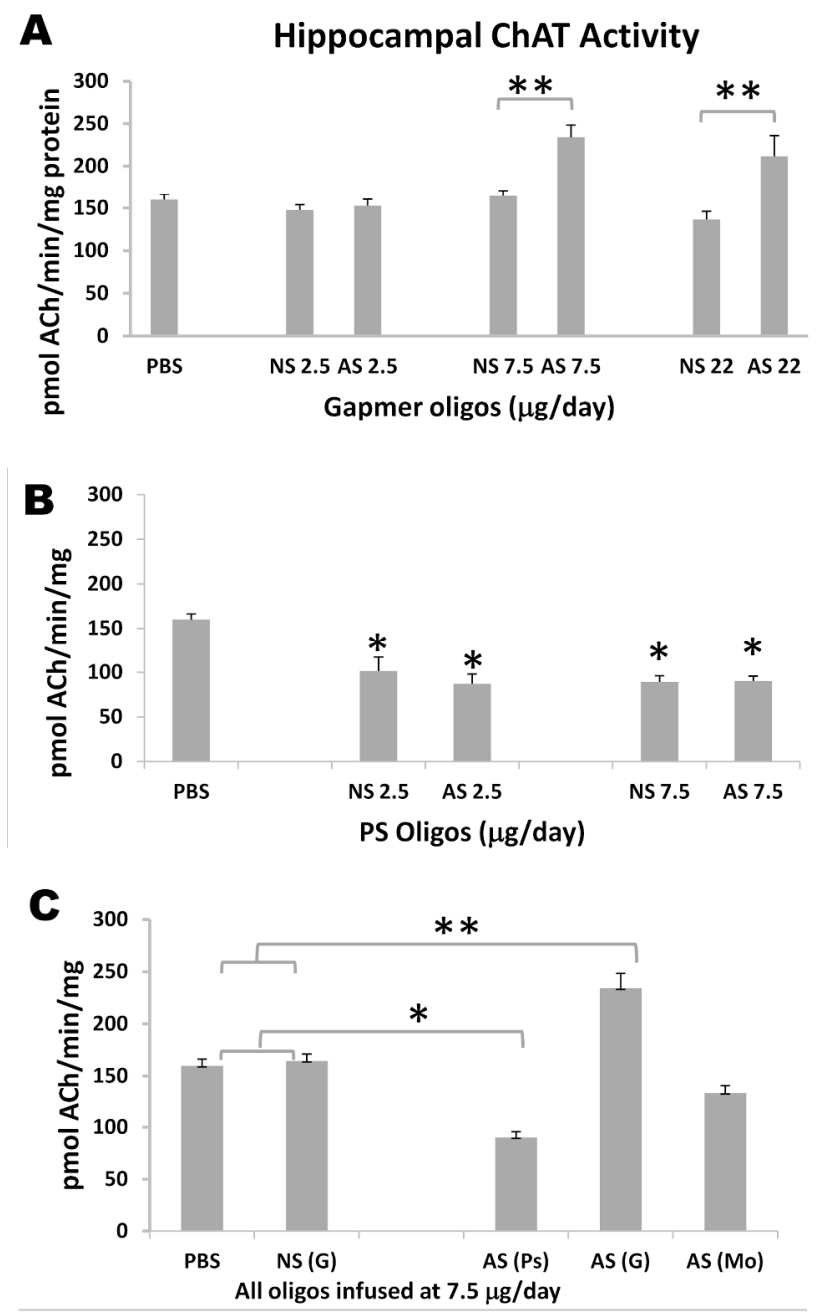

Fig 5 $135 \times 260 \mathrm{~mm}(300 \times 300 \mathrm{DPI})$

\section{Journal of Neuroscience Research}

This article is protected by copyright. All rights reserved. 
figure 6
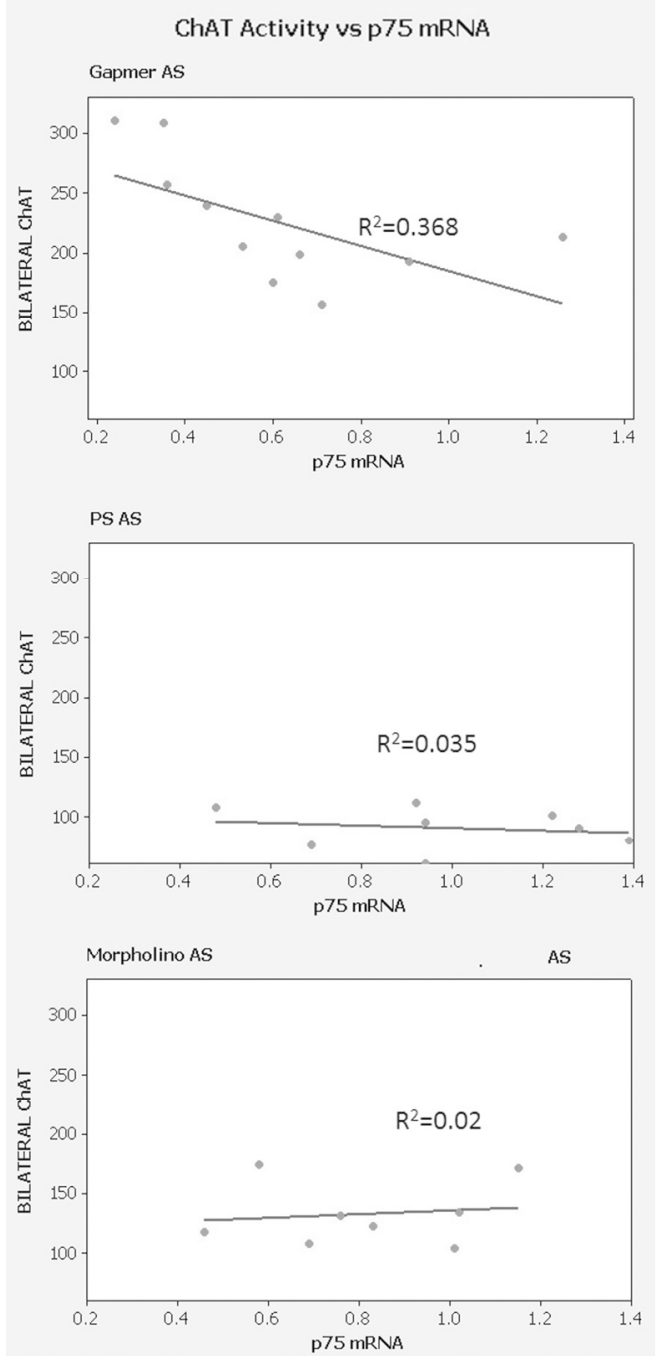

Fig 6 $83 \times 199 \mathrm{~mm}(300 \times 300$ DPI $)$

\section{Journal of Neuroscience Research}

This article is protected by copyright. All rights reserved. 

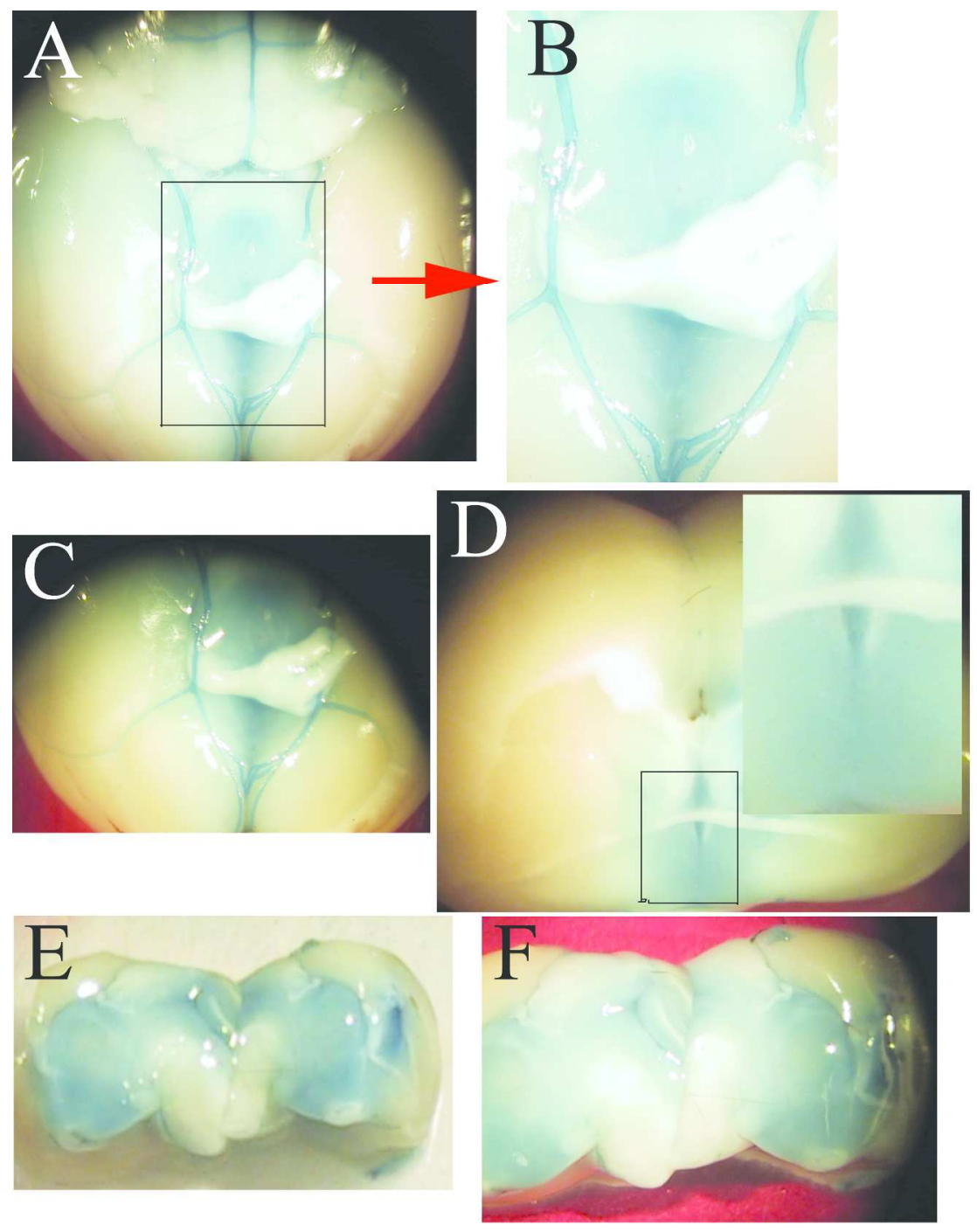

Fig S1. Supplementary figure showing bilateral distribution of trypan blue after midline VDB infusion. $199 \times 279 \mathrm{~mm}$ ( $300 \times 300$ DPI)

\section{Journal of Neuroscience Research}

This article is protected by copyright. All rights reserved. 


\section{SUPPLEMENTARY INFORMATION. Caption for Figure S1}

Fig S1. Correct placement and operation of the cannula outlet was verified by performing a series of cannulations in which Trypan Blue was infused via osmotic minipumps. The surgical procedure and infusion methodology were exactly the same as those carried out for oligos. Trypan blue is likely to have a higher diffusibility in tissue than the highly charged and higher MW oligonucleotides. Therefore the pictures may not portray the actual displacement of infused antisense oligos. They are intended to provide qualitative evidence of bilateral penetration of the basal forebrain region from a single infusion point. A. Inferior view of the intact brain, rostral pole downwards, showing bilateral distribution of trypan blue in the basal forebrain, beneath the optic chiasm. The venous system is filled with trypan blue, reflecting lymphatic drainage and capillary uptake of interstitial trypan blue. B. Magnified view of the inset of figure (A) showing evenly matched penetration of both sides of the basal forebrain. C. Another inferior view of the brain in (A), showing deep penetration bilaterally. D. Coronal view at the level of the joining of the anterior commissures, which was taken as the caudal-most point of the MS/VDB region. The inset shows that the extent of indicator penetration is consistent bilaterally. E. The basal forebrain has been dissected and the right and left sides separated to show the penetration into tissue of the indicator dye. F. Another example with the two sides dissected and spread outwards, similar to E. Infiltration of brain tissue by trypan blue is seen to be equal - at least qualitatively - on both sides.

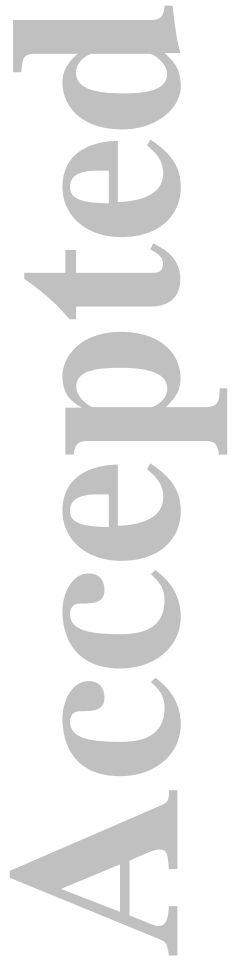




\section{Gapmer anti-p75 antisense}

$=>$ low p75 in MS/VDB

$=>$ high ChAT in hippocampus

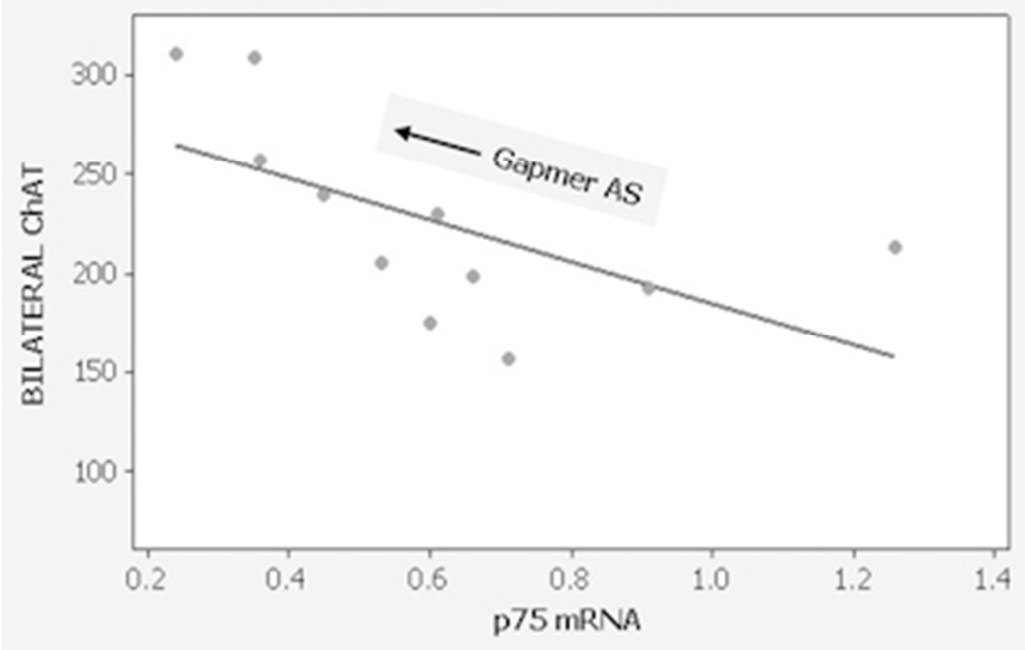

$141 \times 141 \mathrm{~mm}(72 \times 72$ DPI $)$

\section{Journal of Neuroscience Research}

This article is protected by copyright. All rights reserved. 
Gapmer oligos enabled us to downregulate the p75 neurotrophin receptor in the medial septum and vertical limb of the diagonal band of Broca. As hypothesized - consistent with data from the heterozygous and homozygous p 75 knockout mice - this brought about substantial enhancement of hippocampal cholinergic acetyltransferase activity....in normal, adult rats.
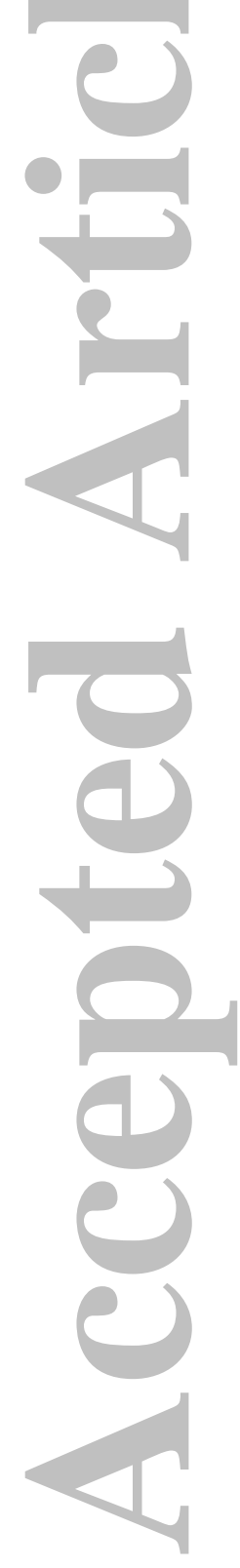

Journal of Neuroscience Research

This article is protected by copyright. All rights reserved. 


\section{University Library}

\section{- M I N E R VA \\ A gateway to Melbourne's research publications}

Minerva Access is the Institutional Repository of The University of Melbourne

Author/s:

Barrett, GL;Naim, T;Trieu, J;Huang, M

Title:

In vivo knockdown of basal forebrain p75 neurotrophin receptor stimulates choline acetyltransferase activity in the mature hippocampus

Date:

2016-05-01

\section{Citation:}

Barrett, G. L., Naim, T., Trieu, J. \& Huang, M. (2016). In vivo knockdown of basal forebrain p75 neurotrophin receptor stimulates choline acetyltransferase activity in the mature hippocampus. JOURNAL OF NEUROSCIENCE RESEARCH, 94 (5), pp.389-400. https:// doi.org/10.1002/jnr.23717.

Persistent Link:

http://hdl.handle.net/11343/290937 